\title{
A Rossby Wave Bridge from the Tropical Atlantic to West Antarctica
}

\author{
Xichen Li, ${ }^{*}$ Edwin P. Gerber, David M. Holland, And Changhyun Yoo ${ }^{+}$ \\ Center for Atmospheric and Oceanic Science, Courant Institute of Mathematical Sciences, New York University, \\ New York, New York
}

(Manuscript received 27 June 2014, in final form 28 November 2014)

\begin{abstract}
Tropical Atlantic sea surface temperature changes have recently been linked to circulation anomalies around Antarctica during austral winter. Warming in the tropical Atlantic associated with the Atlantic multidecadal oscillation forces a positive response in the southern annular mode, strengthening the AmundsenBellingshausen Sea low in particular. In this study, observational and reanalysis datasets and a hierarchy of atmospheric models are used to assess the seasonality and dynamical mechanism of this teleconnection. Both the reanalyses and models reveal a robust link between tropical Atlantic SSTs and the AmundsenBellingshausen Sea low in all seasons except austral summer. A Rossby wave mechanism is then shown to both explain the teleconnection and its seasonality. The mechanism involves both changes in the excitation of Rossby wave activity with season and the formation of a Rossby waveguide across the Pacific, which depends critically on the strength and extension of the subtropical jet over the west Pacific. Strong anticyclonic curvature on the poleward flank of the jet creates a reflecting surface, channeling quasi-stationary Rossby waves from the subtropical Atlantic to the Amundsen-Bellingshausen Sea region. In summer, however, the jet is weaker than in other seasons and no longer able to keep Rossby wave activity trapped in the Southern Hemisphere. The mechanism is supported by integrations with a comprehensive atmospheric model, initial-value calculations with a primitive equation model on the sphere, and Rossby wave ray tracing analysis.
\end{abstract}

\section{Introduction}

Antarctica has experienced a series of dramatic regionalscale climate changes in recent decades. Wintertime surface air temperature observations of the Antarctic Peninsula (Vaughan et al. 2001; Vaughan et al. 2003; Pritchard et al. 2012; Shepherd et al. 2012) and West Antarctica (Bromwich et al. 2013) reveal rapid warming. Satellite measurements show a significant dipolelike redistribution in sea ice (Yuan 2004; Liu et al. 2004; Stammerjohn et al. 2008), with increases in the Ross Sea (Jacobs and Comiso 1997; Yuan and Martinson 2001) and decreases in the Amundsen-Bellingshausen Seas (Zwally et al. 2002; Parkinson 2004). While changes in

\footnotetext{
* Current affiliation: Scripps Institution of Oceanography, University of California, San Diego, La Jolla, California.

${ }^{+}$Current affiliation: Dept. of Environmental Science and Engineering, Ewha Womens University, Seoul, South Korea.

Corresponding author address: Xichen Li, CASPO, Scripps Institution of Oceanography, UC San Diego, 9500 Gilman Drive \#0206, La Jolla, CA 92093-0206.

E-mail: xichenslc@gmail.com
}

radiative forcing from greenhouse gases and ozone have played an important role in Antarctic surface temperature change (e.g., Vaughan et al. 2003; Arblaster and Meehl 2006), these regional-scale changes are strongly influenced by changes in the atmospheric circulation (Thompson et al. 2011; Schneider et al. 2012).

A recent study by Li et al. (2014) suggested that the wintertime changes around the Antarctic Peninsula might in part be driven by warming in the northern and tropical Atlantic Ocean. They found an atmospheric teleconnection, where increased sea surface temperatures (SSTs) in the tropical Atlantic drive an increase in the southern annular mode (SAM) index, deepening the Amundsen-Bellingshausen Sea low in particular. This change in the atmospheric circulation in turn warms the Antarctic Peninsula and drives a redistribution of sea ice. They proposed that this teleconnection was caused by a quasi-stationary Rossby wave train initiated by enhanced convection over the warmer Atlantic SSTs, which propagates around the globe and focuses on the Amundsen Sea region.

In this study, we investigate the seasonality and dynamics of this teleconnection in both reanalyses and a hierarchy of models. We show that the teleconnection 
is active in all seasons except austral summer, and that Rossby wave dynamics can explain this seasonality. In particular, the subtropical jet and midlatitude jet play a critical role in the teleconnection, creating a Rossby waveguide that channels wave activity from the Atlantic around the globe to the Amundsen-Bellingshausen Sea region in all seasons except summer.

The atmospheric circulation around Antarctica is largely influenced by the SAM, a prominent pattern of large-scale climate variability, which is characterized by a zonal mean sea level pressure (SLP) gradient between the subtropical $\left(40^{\circ} \mathrm{S}\right)$ and subpolar $\left(65^{\circ} \mathrm{S}\right)$ region (Thompson and Wallace 2000; Thompson et al. 2000). Variations in the SAM contribute to regional surface warming (Thompson et al. 2011; Schneider et al. 2012), sea ice redistribution (Lefebvre et al. 2004; Lefebvre and Goosse 2005; Sigmond and Fyfe 2010; Stammerjohn et al. 2008), the variability in biological productivity (Lovenduski and Gruber 2005), and the carbon cycle (Butler et al. 2007; Lovenduski et al. 2007). During austral summer, the SAM exhibits a statistically significant positive trend (Marshall 2003), which has been attributed to stratospheric ozone loss (e.g., Thompson and Solomon 2002; Gillett and Thompson 2003). In winter and spring, trends in the SAM are weaker and not statistically significant (Marshall 2003). Stratospheric ozone depletion does not influence the circulation in these seasons, and enhanced internal variability increases the statistical uncertainty.

In West Antarctica and the Amundsen-Bellingshausen Sea region, the climatological circulation is dominated by a semipermanent low pressure system, the AmundsenBellingshausen Sea low (ABSL; Fogt et al. 2012; Turner et al. 2013). The SAM is not entirely zonally symmetric, and the ABSL forms one of the three low pressure centers in the SAM pattern. Fogt et al. (2012) show that as a whole, variations in the ABSL are significantly linked to the SAM variability. The long-term trend of the ABSL is unclear. The ABSL system is dominated by frequent storm activity, such that the region forms the SLP "variance pole" of the Southern Hemisphere; trends in reanalysis are dwarfed by this strong variability. In addition, limited direct observations in this region may affect the reliability of trends derived from the reanalyses.

Numerous studies have linked Antarctic circulation to tropical SST variability. The impact of El NiñoSouthern Oscillation (ENSO) on the Southern Hemisphere has been studied most extensively, beginning with pioneering work by Karoly (1989), who investigated an equivalent barotropic wave train pattern extending from South Pacific to South America. L'Heureux and Thompson (2006) and Fogt and Bromwich (2006) connected ENSO to the SAM, and Stammerjohn et al. (2008) in turn connected the ENSO-related circulation anomalies to sea ice retreat and advance. More recently, Ding et al. $(2011,2012)$ connected warming in the central Pacific to Antarctic circulation trends and established a direct connection through a Rossby wave train toward the ABSL region.

Although SST variability in the tropical Pacific dominates that in all other tropical oceans on interannual time scales, on multidecadal time scales tropical Atlantic SSTs become comparatively more important. Variability in the North Atlantic is characterized by the so-called Atlantic multidecadal oscillation (AMO), which is defined from area-weighted mean Atlantic SST from $0^{\circ}$ to $70^{\circ} \mathrm{N}$ (e.g., Schlesinger and Ramankutty 1994). The AMO exhibits regional SST structure, with significant warming in both the midlatitudes and tropics. Okumura et al. (2012) identified a teleconnection pattern resembling the AMO in correlations between Antarctic ice cores and proxy records of global SSTs. Schneider et al. (2012) found links between the South Atlantic SSTs and West Antarctic warming in austral spring. Li et al. (2014) and Simpkins et al. (2014) connected Antarctic circulation trends and variability to warming in the tropical Atlantic in winter and spring, respectively. Both studies suggest a robust teleconnection between the tropical Atlantic and Antarctic circulation.

After introducing the datasets and models (section 2), we explore the seasonality of the teleconnection in section 3, finding that it is active in all seasons except summer. Experiments with a comprehensive atmospheric model in section 4 suggest that the circulation response is linearly related to the amplitude of Atlantic SST anomalies, consistent with a linear Rossby wave mechanism. We then directly simulate the propagation of Rossby waves in an idealized primitive equation model. The model shows that differences in the background state between summer and winter can explain the seasonality of the teleconnection. In section 5, we gain additional insight from Rossby wave tracing theory (Hoskins and Karoly 1981), which suggests that the subtropical jet over Australia and the west Pacific plays a critical role in creating a Rossby waveguide that channels wave activity from the Atlantic to the ABSL region. The weakening of the zonal winds in summer reduces the effectiveness of the duct, shutting off the teleconnection in summer. We then summarize and conclude our study in section 6 .

\section{Datasets and models}

We use two atmospheric reanalysis datasets: the Modern-Era Retrospective Analysis for Research and Applications (MERRA; Rienecker et al. 2011) and the European Center for Medium-Range Weather Forecasts (ECMWF) Interim Re-Analysis (ERA-Interim; Dee 
et al. 2011). Monthly-mean data from MERRA and ERA-Interim from January 1979 to December 2012 were used.

The Hadley Centre Sea Ice and Sea Surface Temperature (HadISST) dataset is used to calculate time series of the tropical Atlantic SSTs, and to provide boundary conditions for the atmospheric model simulations. The HadISST datasets span from 1870 to the present (Rayner et al. 2003). To ensure the robustness of our results, we compared all our results with equivalent analysis of the Kaplan extended SST data version 2 (http://www.esrl. noaa.gov/psd/data/gridded/data.kaplan_sst.html). The two datasets show the same spatial and temporal variability, and therefore the analysis result of Kaplan SST data is not shown in this paper.

We use the National Center for Atmospheric Research (NCAR) Community Atmosphere Model version 4 (CAM4) to simulate the atmospheric response to SST changes in the Atlantic. We employ the finitevolume version of the dynamical core with a horizontal resolution of approximately $2^{\circ}$. The sea surface temperature and the sea ice concentration are prescribed according to observational data, as a lower boundary condition of the atmospheric model. We use the Community Land Model (CLM) and the thermodynamic module of the Community Sea-Ice Model (CICE) to estimate heat and moisture fluxes at the land-air and ice-air interfaces, respectively. As a result, the only external forcing of these experiments is the lower boundary condition over the oceans.

To simulate Rossby wave dynamics, we use the spectral dry dynamical core of the National Oceanic and Atmospheric Administration (NOAA)/Geophysical Fluid Dynamics Laboratory (GFDL) model (e.g., Held and Suarez 1994). We effectively use the model as a numerical solver of the dry primitive equations to compute the response to tropical warming. Jin and Hoskins (1995) showed that warming of the tropical ocean increases atmospheric deep convection locally, driving anomalous divergence of the large-scale atmospheric flow. The dry, atmosphere-only dynamic core cannot represent these processes, so we approximate the effect of SSTs by a prescribed warming, which mimics the effect of deep convection. As in Yoo et al. (2012), we assume that convective heat projects primarily onto the first baroclinic mode, with maximum heating in the midtroposphere. Divergence in the presence of a vorticity gradient in turn generates Rossby wave trains (e.g., Sardeshmukh and Hoskins 1988).

The goal is to simulate the time-evolving response of the atmosphere to convective heating as a function of the background climatology. A conventional initial-value calculation, however, will not work, as the three-dimensional climatological flow itself depends critically on the presences of eddies, whose heat and momentum fluxes balance radiative and convective forcing. The trick is to use the model itself to compute the tendency of the climatology to drift in time, and then apply it in reverse to steady the model about a given climatology (Franzke et al. 2004; Yoo et al. 2012). We apply this procedure using climatologies based on June-August (JJA) and December-February (DJF) means from ERA-Interim. We then impose the idealized heating perturbation over the tropical Atlantic to compute the Rossby wave response as a function of the background state. Apart from the forcing to maintain the background state and the heating perturbation, we employ Newtonian cooling to the perturbation temperature only, where a perturbation is defined as the anomaly from the initial state. In addition, the model includes Rayleigh friction on the nearsurface layers and the fourth-order horizontal diffusion as in Held and Suarez (1994), both of which effectively act on the perturbation alone. We run the model with triangular truncation at wavenumber 42 (T42), which corresponds roughly to a $3^{\circ}$ grid spacing.

\section{A three-season teleconnection between the Atlantic and Antarctica}

The tropical Atlantic has exhibited significant warming in the past three decades. The linear trend in SSTs from 1979 to 2012 is shown in Fig. 1. Nearly the entire region has warmed over this period, but the warming is substantially larger north of the equator (Fig. 1a). The pattern bears a strong resemblance to the AMO pattern of variability (e.g., Fig. 1 of Li et al. 2014). We remove the annual cycle in SSTs and form a monthly mean time series of the spatial average SST from $20^{\circ} \mathrm{S}$ to $20^{\circ} \mathrm{N}$ in Fig. 1b. Tropical Atlantic SSTs are correlated with overall North Atlantic temperatures $(R=0.77)$, and the positive trend over this period of approximately $0.5 \mathrm{~K}$ is consistent with the ascent of the AMO index over this period. The trend in tropical Atlantic SSTs has no seasonal variation, as illustrated in Fig. 2. The standard deviation in tropical mean SSTs is also roughly equivalent in all seasons, at approximately $0.2 \mathrm{~K}$.

We remove the linear trend from the SST time series, yielding a detrended index of tropical Atlantic SSTs in Fig. 1c. The interannual variability of the ocean temperature is small relative to the warming trend: the standard deviation of the SST is approximately $0.2 \mathrm{~K}$, compared to a $0.5-\mathrm{K}$ trend. It is nevertheless critical to remove linear trends to find a reliable relationship between Atlantic SSTs and the Antarctic circulation in the reanalyses. Otherwise the regressions may be polluted by other trends in the climate system over the period, both forced changes associated with greenhouse gas 

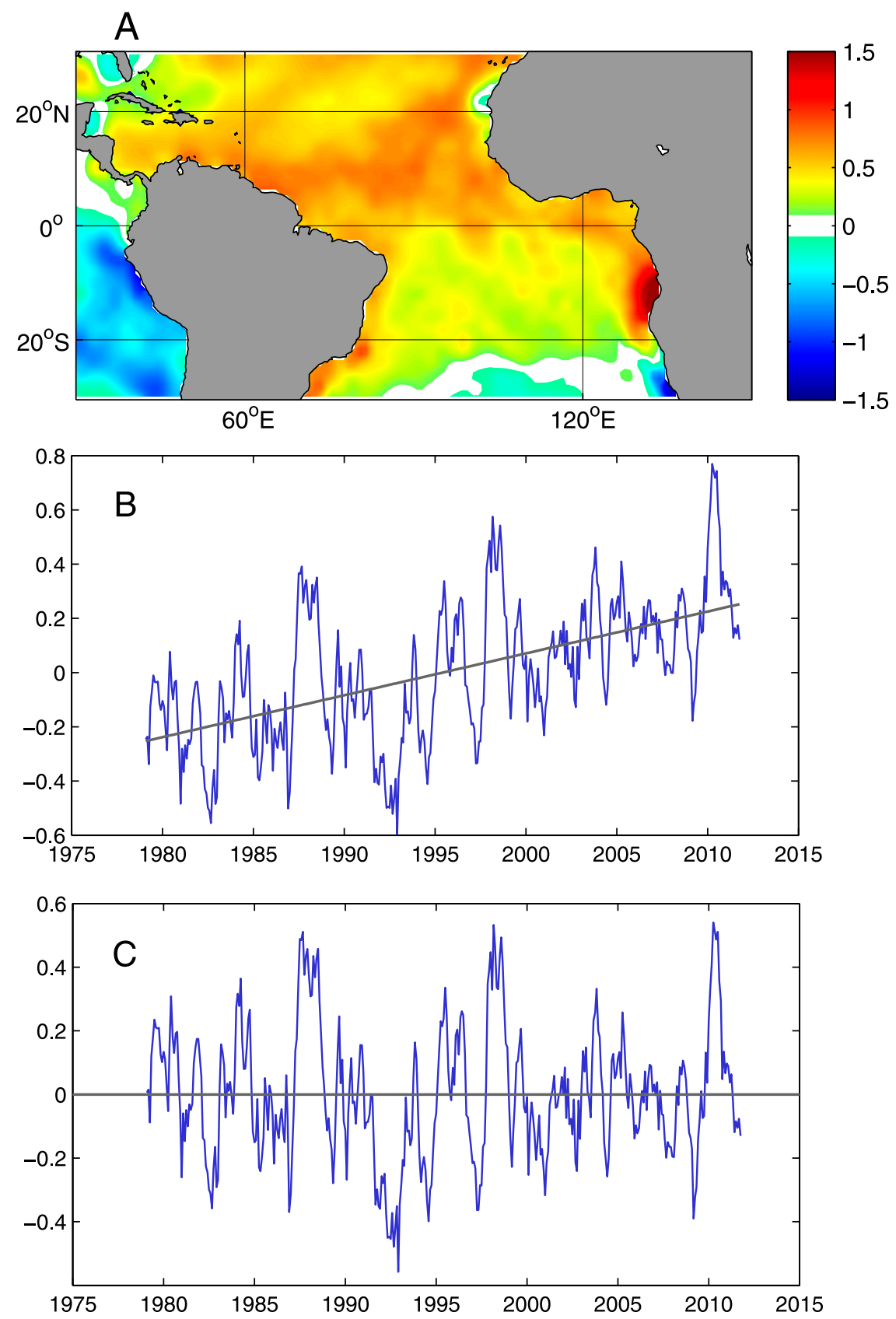

FIG. 1. The trend and variability of tropical Atlantic sea surface temperature (SST) since 1979; the unit of the trend is $\mathrm{K}(34 \mathrm{yr})^{-1}$. (a) The spatial pattern of the SST trend. (b) The blue curve shows the spatial mean SST time series (K) over the tropical Atlantic region, while the linear trend is indicated by the gray line. (c) The detrended time series of the spatial mean SST $(\mathrm{K})$, which is used in the regression analysis.

increase and stratospheric ozone loss and spurious changes due to changes in the observing system.

\section{a. The teleconnection in reanalysis}

Li et al. (2014) showed that the circulation around Antarctica is significantly correlated with tropical Atlantic
SSTs in austral winter. We extend their analysis in Figs. 3a,c,e,g, linearly regressing 200-hPa geopotential height from detrended MERRA reanalysis onto the detrended tropical Atlantic time series for each season separately. The SST time series is detrended and normalized for each season, so that the color mapping shows 


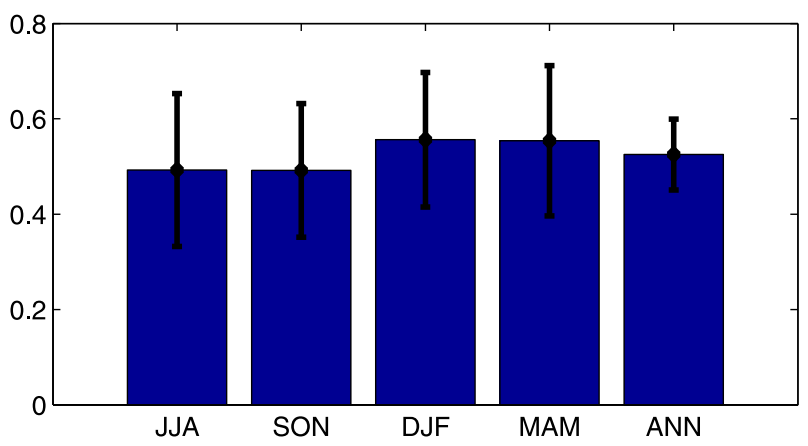

FIG. 2. The SST trend (K) over the tropical Atlantic region $\left(20^{\circ} \mathrm{N}-20^{\circ} \mathrm{S}\right)$ for the four seasons and the annual mean from 1979 to 2012. The error bars indicate the $95 \%$ confidence interval by Student's $t$ test. The SST warming trend is significant in all four seasons.

the change in geopotential height associated with a onestandard-deviation change in SSTs. The significance of the regression results is estimated using a Student's $t$ test, where the autocorrelation of the time series is accounted for by an appropriate reduction in the degrees of freedom (Bretherton et al. 1999).

In austral winter (JJA), spring [September-November (SON)], and autumn [March-May (MAM)], the regression results reveal a meridional dipole anomaly in height in association with tropical warming. When the tropical Atlantic is warm, there is a broad positive anomaly in geopotential height in the subtropics, and negative anomalies over Antarctica: a pattern that resembles the SAM. There is significant zonal structure to the pattern, however, particularly in the ABSL region, which exhibits a strong decrease in geopotential height associated with Atlantic warming. Regression of SLP on the tropical Atlantic warming time series (not shown) reveals a similar structure, suggesting that the pattern is highly barotropic. We also validated these regression results with ERA-Interim, and find essentially the same results: the spatial correlation of the $30^{\circ}-90^{\circ} \mathrm{S}$ regression results in ERA-Interim and MERRA are 0.94, 0.98, and 0.92 for MAM, JJA, and SON, respectively.

During austral summer, however, the pattern is fundamentally different. The decrease in geopotential height around Antarctic is much weaker, and a positive anomaly appears in the ABSL region. More importantly, regression analysis based on ERA-Interim (not shown) reveals a different pattern from that in MERRA (spatial correlation $=0.44$ poleward of $30^{\circ} \mathrm{S}$ ), suggesting that the summer teleconnection is not robust.

We summarize the regression results in Fig. 4, plotting the anomaly in geopotential height in the ABSL region (purple box, Fig. 3a) associated with a one-standarddeviation warming of the tropical Atlantic SSTs for each season. For all seasons but summer, we find a statistically significant deepening of the ABSL in association with warming of the tropical. In summer, on the other hand, the ABSL-tropical Atlantic connection is statistically insignificant, and, if anything, exhibits the opposite sign.

While detrending the Atlantic SST time series prevents contamination of the regressions by trends in the reanalyses, one cannot rule out potential covariability with other modes in the climate system. Given the observed relationships between ENSO and central Pacific with the Amundsen-Bellingshausen Seas region (e.g., Fogt and Bromwich 2006; Ding et al. 2011), we also regressed geopotential height against a time series of tropical Atlantic SST where all variability linearly coherent with the Niño-3 or Niño-4 SST indices was removed. The regression results (not shown) are similar to Fig. 3, although the confidence level is reduced, particularly when central Pacific SSTs tracked by the Niño-4 index are removed. This suggests that regression analysis may conflate signals from the Pacific and Atlantic together, especially when the Pacific dominates the tropical interannual variability. As regression analysis cannot establish a causal link between the tropical Atlantic and ABSL region, we turn to a hierarchy of atmospheric models to better investigate the causality, mechanism, and physical dynamics behind the teleconnection. While the MERRA regression is directed at interannual variability, the CAM4 simulations are perturbation experiments that imply more on multidecadal time scales.

\section{b. An atmospheric model simulation of the teleconnection}

We first use a comprehensive atmospheric model (CAM4) to show that the SSTs are indeed driving the atmospheric response. In this experiment, we compare a simulation with modified SSTs to a control integration where all other forcings are identical. In the control integration, the seasonally evolving SSTs are set to a climatology based on HadISST averaged from 1976 to 1985. Greenhouse gases and the stratospheric ozone concentrations are also specified as their mean values for this period. Figures $3 b$,d,f,h show, as a function of season, the difference in the $200-\mathrm{hPa}$ geopotential height between the control run and a second simulation in which only SSTs in the tropical Atlantic are perturbed. This SST perturbation is intended to represent the multidecadal variability in the Atlantic, and so set to the observed $1979-2012$ changes in the Atlantic from $20^{\circ} \mathrm{S}$ to $20^{\circ} \mathrm{N}$. The change varies slightly in each month of the year (i.e., January is forced with the 1979-2012 changes for January, and so forth). As indicated in Fig. 2, however, the SST changes are fairly uniform in all seasons, and well characterized by the annual pattern shown in Fig. 1a. To ensure the statistical robustness of the response to SST 


\section{0mbar Geopotential Height Anomaly}
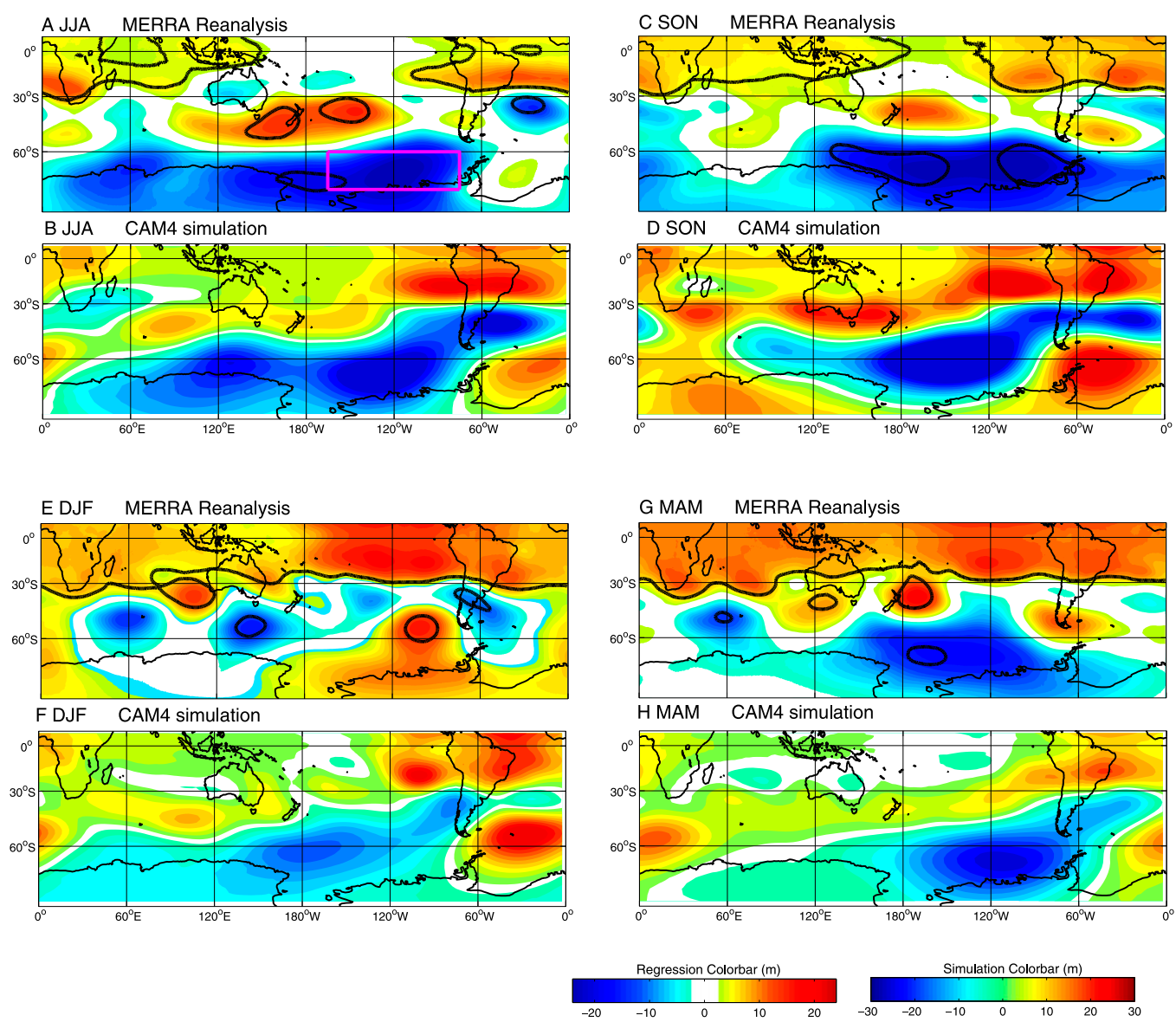

FIG. 3. The link between 200-hPa geopotential height (GPH, m) and tropical Atlantic SSTs in MERRA reanalysis and CAM4 simulations as a function of season. (a),(c),(e),(g) Regression of MERRA 200-hPa GPH against the detrended tropical Atlantic SST time series in JJA, SON, DJF, and MAM, respectively, for the period 1979-2012. The color shading (left color bar) shows the spatial distribution of the regression slopes with the areas within the black contour indicating the region with a significance level $>95 \%$, by a Student's $t$ test. (b),(d),(f),(h) The CAM4 model response to the change in tropical Atlantic SSTs in JJA, SON, DJF, and MAM, respectively, from 1979 to 2012 (right color bar), as detailed in the text. A Student's $t$ test indicates that the response is robust at nearly every point (both the control and perturbation integrations were simulated for $100 \mathrm{yr}$ ); hence, the regions of significance are not singled out. The regression and model simulations suggest that a warmer tropical Atlantic is associated with a stronger phase of the southern annular mode (SAM) and deeper Amundsen-Bellingshausen Seas low (ABSL) in all seasons except austral summer (DJF). The purple box in (a) represents the area around Amundsen Sea and will be used to calculate the Amundsen Sea Anomaly for both the model and regression results.

perturbations, both the control and perturbation simulations were spun up for 10 model years and then run for another 100 years.

While the regression results are based on subdecadal SST variability and the model was forced with the multidecadal change in Atlantic SSTs, both are relevant to an intermediate time scale where the atmosphere has equilibrated in response to the tropical ocean perturbation, but does not feed back on the mid- and highlatitude ocean. Such feedback is explicitly prevented in the fixed SST model integrations, and minimized in the regression analysis by filtering out the longer time scales at which the high-latitude ocean might respond to the atmospheric circulation changes.

The difference in the simulation results between the forced and the control runs represents the model response to this additional SST forcing. For autumn, winter, and spring, the modeled response of $200-\mathrm{hPa}$ geopotential height is very similar to the regression results: warming of the tropical Atlantic drives a dipolar anomaly in geopotential height between the high and low latitudes, projecting strongly onto a negative index 


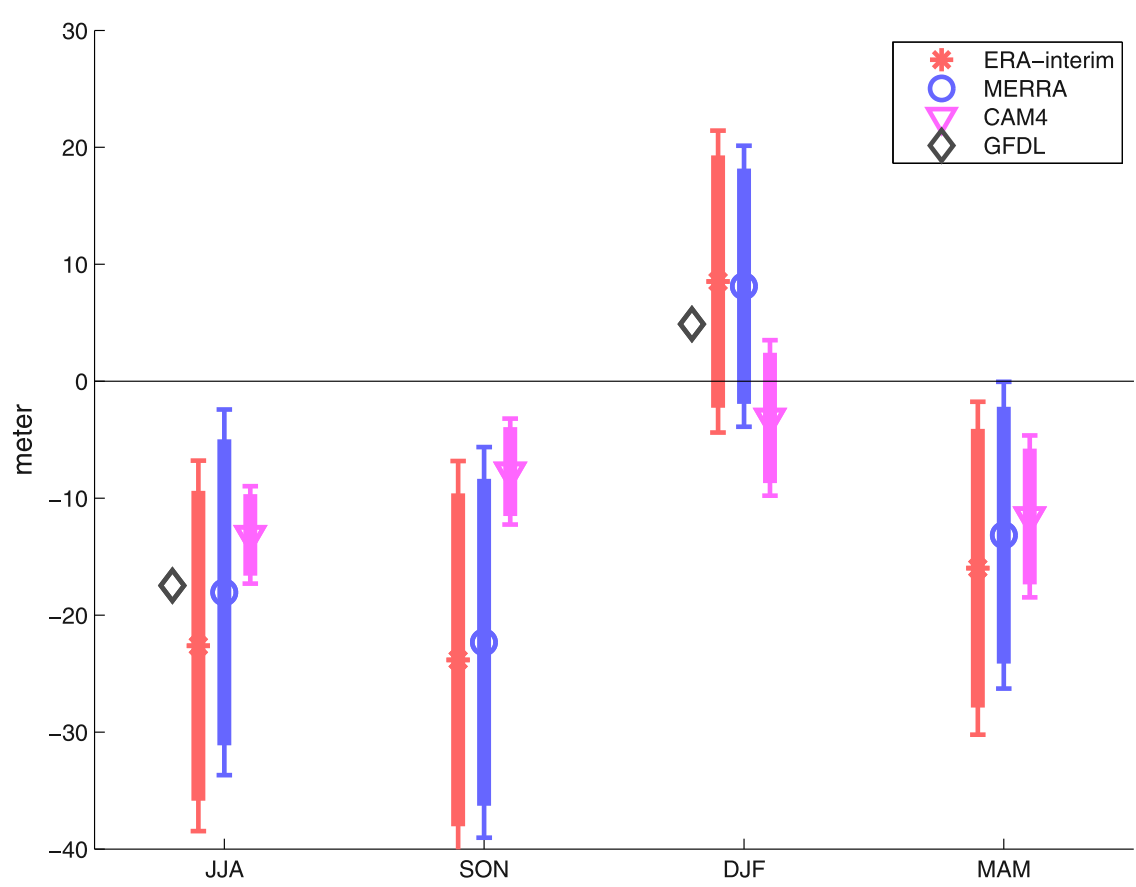

FIG. 4. Area-weighted mean geopotential height (GPH, m) anomaly over the box region $\left(60^{\circ}-75^{\circ} \mathrm{S}, 75^{\circ}-165^{\circ} \mathrm{W}\right.$, shown in Fig. 3a) in response to the tropical Atlantic warming in different analyses and during the four seasons. The red dots show the GPH anomaly in the ERAInterim regression; the blue circles show the GPH anomaly in MERRA regression; the purple triangles show the CAM4 simulation results; and the black diamonds show the GFDL response. The responses in MAM, JJA, and SON show coherent signals where the GPHs are lowered in regressions and CAM4 simulations; and the GFDL JJA simulations agree well with the other three analyses. However, the results in DJF do not agree with each other and do not show a coherent decrease of GPH. The thick and thin error bars show the $90 \%$ and $95 \%$ confidence level, respectively.

of the SAM. The model also captures the zonally asymmetric structure of the teleconnection pattern, indicating that warming over the Atlantic deepens the ABSL in particular.

The model, however, slightly underestimates the strength of the teleconnection relative to the regression analysis, particularly in spring. The SST regressions (Figs. 3a,c,e,g) are normalized by the standard deviation of the subdecadal variability for each season, which is roughly half of the trend. In Fig. 4 we normalize the CAM response over the ABSL to make a more quantitative comparison. The amplitude is nearly the same in winter and autumn, but only half the amplitude in spring. In summer, the model suggests a very weak high-latitude response (Fig. 3f); the pattern does not project very strongly onto the SAM, and differs from the MERRA pattern (Fig. 3e) and ERA-Interim pattern (not shown).

The model results show the response of the atmosphere to the change of the tropical Atlantic SSTs between 1979 and 2012 (Fig. 1), indicating a causal pathway between the tropical Atlantic SSTs and circulation anomalies in the Amundsen Sea region. One cannot rule out the possibility, however, that the tropical Atlantic SSTs themselves are influenced by or interact with SSTs in other basins (i.e., the Pacific).

\section{A Rossby wave train mechanism}

Li et al. (2014) suggested that the teleconnection was created by a Rossby wave train, which propagates from the tropical Atlantic to the ABSL. Here we use the seasonality of the teleconnection to establish the mechanism. We find that Rossby wave dynamics can both explain the amplitude of the teleconnection and its seasonality.

\section{a. Linearity of the circulation response to tropical warming}

We first establish that the circulation response to tropical Atlantic warming in CAM4 is linear in all the seasons where the teleconnection is active, consistent with linear Rossby wave dynamics. We perform four additional perturbation simulations where only SSTs in the tropical Atlantic are modified. In two, we reverse the 
A 200hPa GPH response to standard (1X) Atlantic Forcing

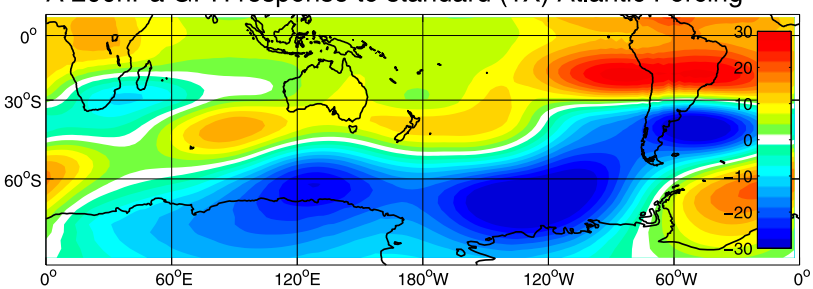

$\mathrm{B} 200 \mathrm{hPa}$ GPH response to (2X) Atlantic Forcing

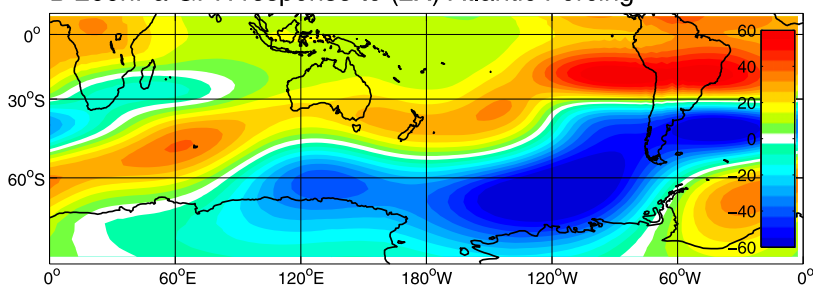

$\mathrm{C} 200 \mathrm{hPa}$ GPH response to (3X) Atlantic Forcing

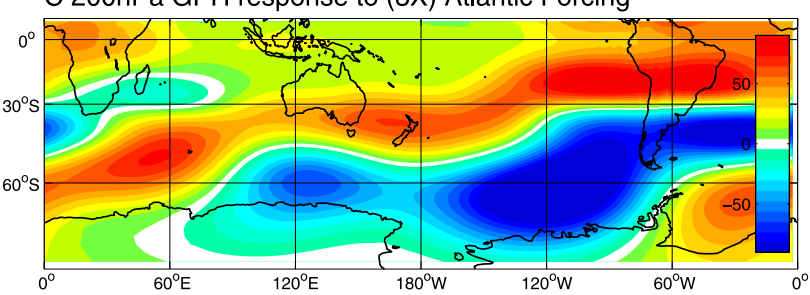

D 200hPa GPH response to (-1X) Atlantic Forcing

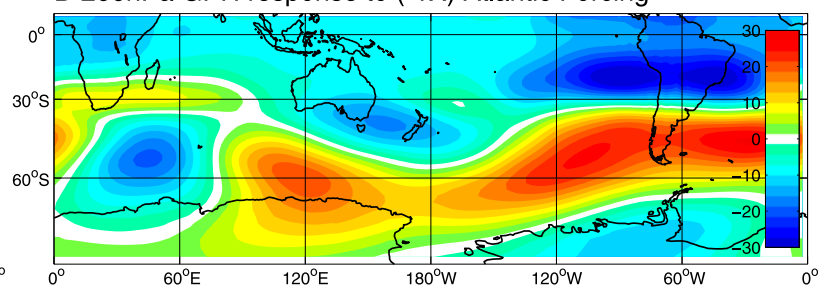

E 200hPa GPH response to (-2X) Atlantic Forcing

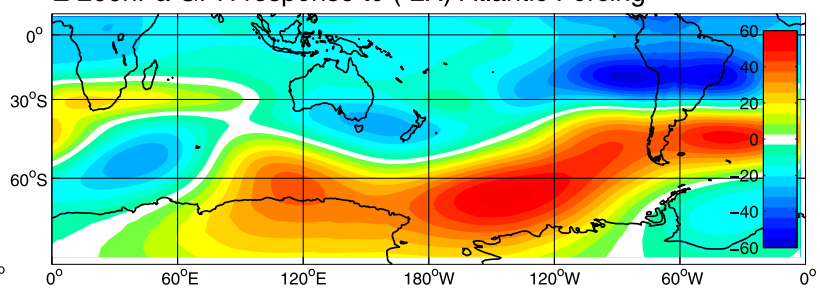

FIG. 5. Linearity experiments for JJA tropical Atlantic warming, using the CAM4 simulation. (a) The model response of 200-hPa geopotential height (GPH) to the standard tropical Atlantic SST forcing (SST trend since 1979 to 2012; i.e., a duplication of Fig. 3b). Also shown are model responses to (b),(c) 2 and 3 times and (d),(e) -1 and -2 times the standard SST forcing, respectively. To better compare the simulation results, the color bar of each panel is adjusted according to the intensity of the SST forcing. For example, the range of the color bar in (c) (3 times standard forcing) is 3 times the range in (a) (standard forcing).

sign of the SST changes, multiplying it by -2 or -1 . We denote these simulations the $-2 \mathrm{X}$ and $-1 \mathrm{X}$ cases. In the other two experiments, we double and triple the strength of the SST perturbation, referring to them as the $2 \mathrm{X}$ and $3 \mathrm{X}$ cases. The results of these simulations are compared with model response to the observed SST changes shown in Fig. 3, denoted as the $1 \mathrm{X}$ case.

The austral winter responses of the 200-hPa geopotential height to tropical Atlantic SSTs in the five simulations are shown in Fig. 5. The color bars are adjusted according to the magnitude of the SST forcing in each experiment; that is, for the $2 \mathrm{X}$ case shown in Fig. 5b, the color bar is double that of the $1 \mathrm{X}$ case shown in Fig. 5a. Thus, the fact that Figs. 5a-c appear nearly identical suggests that the response to SST warming is nearly linear. Moreover, the fact that Figs. 5d and 5e are nearly equal and opposite in appearance suggest that the SST cooling over the Atlantic causes the opposite response to warming, shallowing the ABSL.

The response is fairly linear in other seasons as well, as shown in Fig. 6. The upper panels compare the amplitude of the geopotential height response to varying SST intensity. We regress the response of each simulation against the response in the $1 \mathrm{X}$ case; if the response to tropical Atlantic were purely linear, all plots would line up against the 1:1 slope line (black curves). Agreement is particularly strong in the winter and autumn. In summer, the response to tropical Atlantic anomalies grows sublinearly, whereas in spring the response to negative anomalies is weaker than expected.

The lower panels in Fig. 6 show the pattern correlation between the $1 \mathrm{X}$ response and the response in the other simulations. The correlation reveals the coherency between the spatial structures; if the response were purely linear, the coefficients would be either 1 or -1 . The pattern correlation is high in all the positive SST integrations but deviates from -1 in many of the negative SST simulations. In particular, the pattern correlation is relatively weak in the spring simulations, Fig. 6f, explaining in part the sublinear growth in the regression slope shown in Fig. 6b. In contrast, the sublinear growth of the anomalies in summer (Fig. 6c) is not due to a weakening of the pattern correlation (Fig. $6 \mathrm{~g}$ ).

Overall, however, these additional perturbation experiments suggest that the atmospheric response to Atlantic SST anomalies from -1 to $1.5 \mathrm{~K}$ (from -2 to 3 times the observed changes between 1979 and 2012) is remarkably linear. This validates the linear assumption 
A Linearity-Regression JJA

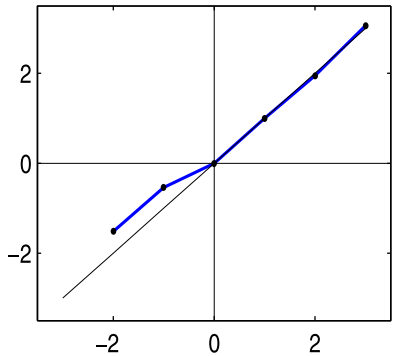

E Linearity-Correlation JJA

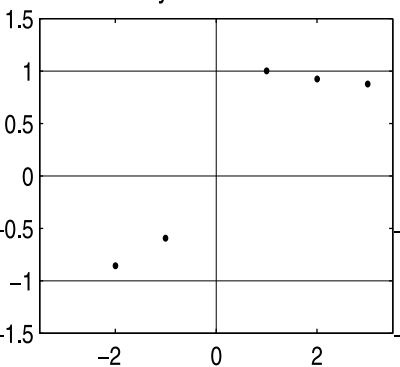

B Linearity-Regression SON

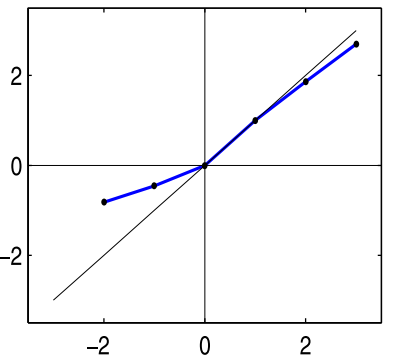

F Linearity-Correlation SON

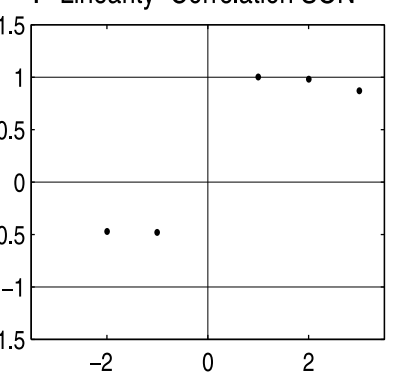

C Linearity-Regression DJF

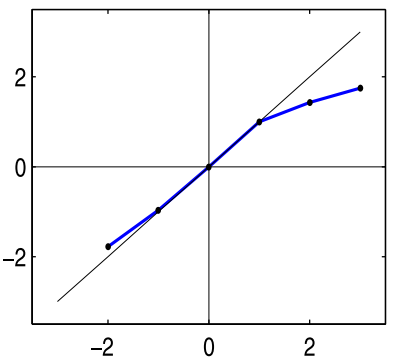

G Linearity-Correlation DJF

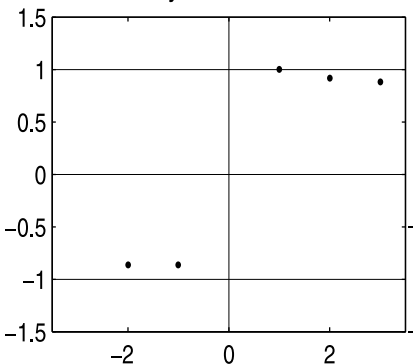

D Linearity-Regression MAM

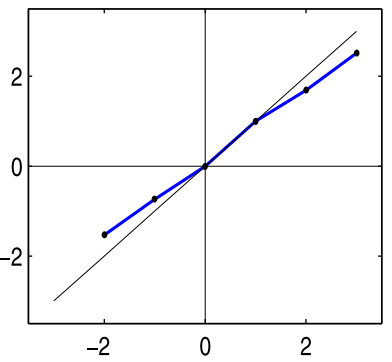

$\mathrm{H}$ Linearity-Correlation MAM

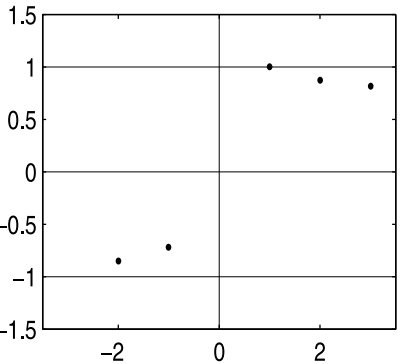

FIG. 6. Analysis of the model linearity using the simulation results. (a)-(d) The regressed spatial pattern of the geopotential height model responses in the five linearity simulations (as shown in Fig. 5) against the standard model results (Fig. 5a) in (left)-(right) four different seasons. The spatial pattern regression and correlation was conducted over the entire Southern Hemisphere, south to $20^{\circ} \mathrm{S}$. The $x$ axis is the magnitude of external forcing (in units of $\times$ the standard SST forcing), while the $y$ axis is the regression parameters (with respect to the model response to the standard SST forcing). The thick blue curves with black dots show the regression slopes. The thin black lines show the 1:1 linear slope and serve as the reference of pure linear relationship. For a purely linear response, the thick blue curve should overlap the thin black line. (e)-(h) The black dots similarly represent the correlation coefficients instead of regression slopes. For a purely linear response, the black dots should fall on the two horizontal black lines representing a correlation $=1$ and correlation $=-1$.

behind the regression analysis of the reanalyses and supports a linear mechanism.

\section{b. Rossby wave dynamics in a dry primitive equation model}

To zero in on the physical mechanism of the teleconnection, we next utilize an idealized atmospheric model, the GFDL spectral dry dynamical core. This model cuts out all the physical parameterizations employed by CAM4, allowing us to focus exclusively on the Rossby wave dynamics. Following Seo and Son (2012) and Yoo et al. (2012), we use it to assess the impact of the background state on circulation response to tropical warming.

In Fig. 7 we compare two initial value calculations that differ only in their background climatology, one initialized with winter conditions and the other with summer conditions. The vertical structure and amplitude of the heating perturbation are exactly as in Yoo et al. (2012) [Eq. (2)], and capture the intensity of observed convection anomalies. We show the flow in six snapshots on day 3 through day 18 with 3 -day intervals. The wave train has reached maximum amplitude by this final time. In addition, these initial-value calculations cannot be run indefinitely, as the flow eventually becomes baroclinically unstable, and the steadying tendency is no longer able to maintain the background state.

In winter (Figs. 7a-f), divergence associated with convective heating over the tropical Atlantic lifts the geopotential height locally (day 3 ). This initial perturbation begins to generate stationary Rossby wave trains that extend to the south (day 6) and then to the east (days 9 and 15). Rather than propagating along a straight path across the sphere (or great circle, as would be expected in the absence of inhomogeneity of the background state), the wave train propagates zonally, finally converging over the Amundsen-Bellingshausen Seas area within two weeks. This drives a pronounced negative anomaly over the region from day 12 to day 18 .

In the summer experiment, the initial response in geopotential height is nearly the same in the winter integration (cf. Figs. $7 \mathrm{a}$ and $7 \mathrm{~g}$ ), reflecting the direct response of the tropical atmosphere to heating. In contrast to the winter integration, however, the resulting Rossby wave train (Figs. 7h-1) never builds up in strength and barely extends to the International Date Line. As highlighted in Fig. 4, the Rossby wave response in the ABSL region to tropical heating is substantially stronger in 

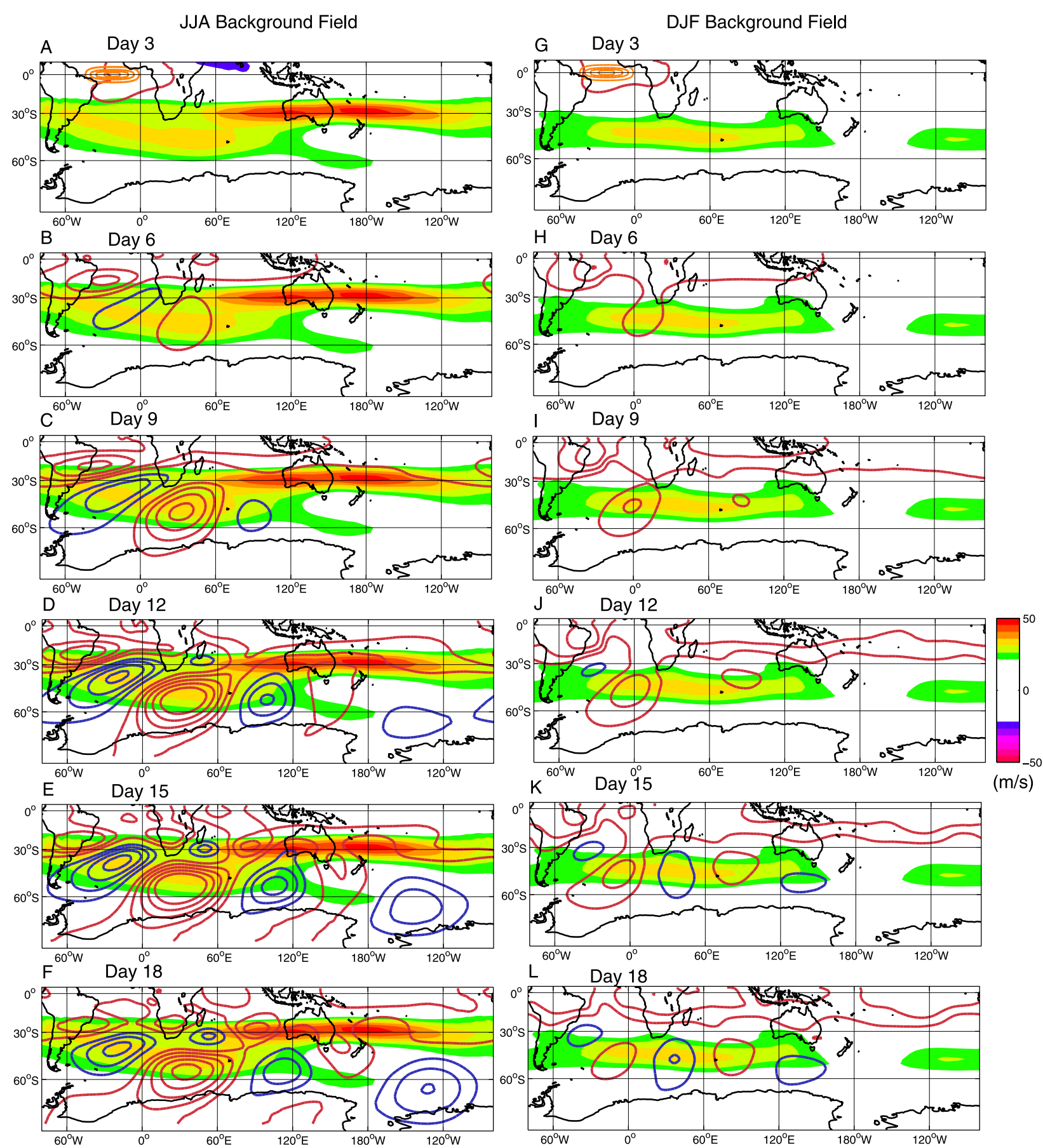

FIG. 7. Comparison of the stationary Rossby wave response in the austral (left) winter and (right) summer GFDL idealized simulation for (top)-(bottom) days 3 to 18 with a three-day interval from the initial perturbation. The red (blue) contours show 200-hPa geopotential height positive (negative) anomaly (contour interval $10 \mathrm{~m}$ ), while the color shading shows the climatological mean 200-hPa zonal wind. Both of these two simulations are forced by the same initial perturbation whose spatial pattern is shown as the orange contours in (a) and (g) (a Gaussian distribution, centered at $20^{\circ} \mathrm{W}$ on the equator, with the meridional span of $\pm 5^{\circ}$, and the zonal span of $\pm 22.5^{\circ}$ ). Both of these two stationary Rossby wave trains propagate along the south edge of the subtropical jet. The wave trains can propagate to the Amundsen Sea area in austral winter, but terminate at the Ross Sea in austral summer. 
A. JJA day3 RWS

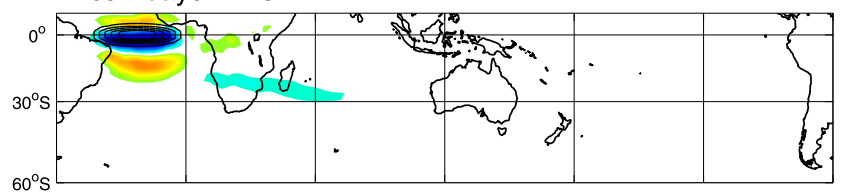

B. JJA day6 RWS
C. DJF day3 RWS

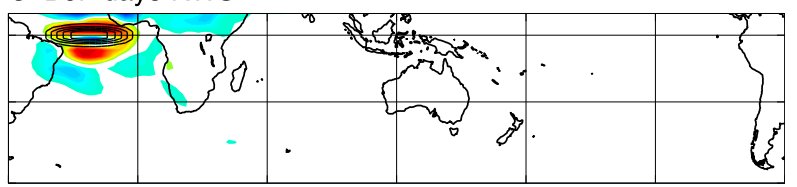

D. DJF day6 RWS

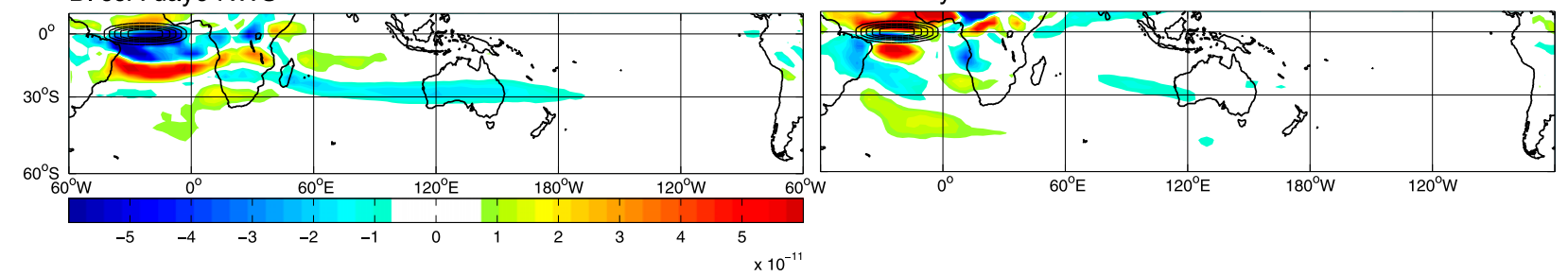

FIG. 8. Color shading showing the day 3 and day 6, 200-hPa Rossby wave source (RWS) anomaly in GFDL dry-dynamical core initial value calculations for (a),(b) JJA and (c),(d) DJF, respectively. The unit of the color shading is $\mathrm{s}^{-1}$. The black contours show the initial perturbation (convective heating).

winter than in summer. The model suggests that the anomaly may even have opposite sign in summer, as observed with MERRA and ERA-Interim.

Despite the difference in the resulting wave train in the two seasons, in both cases the stationary Rossby wave trains tend to propagate eastward along the southern edge of the midlatitude jet across the South Atlantic and Indian Oceans. During summer, the jet is weaker than in winter and only extends to the east coast of Australia, and the subtropical jet over Australia and the west Pacific is nearly absent in this season. Correspondingly, the summertime Rossby wave train dies out before reaching the date line. In the wintertime, the wave train continues on to the ABSL region. This suggests that the Rossby wave propagation depends critically on the presence and intensity of the subtropical jet and midlatitude jet, as observed in previous theoretical (e.g., Hoskins and Karoly 1981) and observationally based studies (e.g., Ding et al. 2012).

\section{A Rossby wave channel created by the subtropical jet}

The initial-value calculations indicate that the seasonal cycle of the teleconnection depends critically on the seasonality of the background state. The background flow can influence both the generation and propagation of Rossby waves. We explore these two impacts separately, first analyzing seasonal changes in the source of Rossby wave activity, and then isolating the impact of the seasonal cycle on the propagation by performing ray tracing trajectory analysis. We find that both influences may play a role in the seasonality of the teleconnection.

\section{a. The Rossby wave source}

Our initial-value calculations show a well-developed Rossby wave train in response to convective heating at the equator in a region of easterly flow. The results are nearly identical (not shown) if we move the heating all the way north of the equator. Rossby waves, however, can only propagate in regions of westerly flow. How then does convective heating in the northern-tropical Atlantic reach the Southern Hemisphere? The key lies in the fact that the generation of Rossby wave activity is nonlocal, and depends on the total extent of the divergent flow associated with the convective heating. As shown by Sardeshmukh and Hoskins (1988), Rossby wave activity in the upper troposphere is generated by divergent flow in the presence of nonzero absolute vorticity. The Rossby wave source (RWS) $S$ is given by

$$
S=-\nabla \cdot \zeta v_{\chi}=-\zeta^{\prime} \nabla \cdot \bar{v}_{\chi}-\bar{\zeta} \nabla \cdot v_{\chi}^{\prime}-v_{\chi}^{\prime} \cdot \nabla \bar{\zeta}-\bar{v}_{\chi} \cdot \nabla \zeta^{\prime},
$$

where $\zeta$ is the vertical component of the absolute vorticity, and $v_{\chi}$ is the divergent component of velocity. Anomalous deep convection in response to increased SSTs drives anomalous divergence of the large-scale flow that extends away from the local heating by modulating the Hadley and Walker circulations. This process has been discussed in detail in a recent study by Simpkins et al. (2014).

Figures $8 \mathrm{a}$ and $8 \mathrm{~b}$ show the initial response of the Rossby wave source $S$ to tropical heating in the JJA initial value calculation shown in Figs. 7a-f. We focus on $S$ in the first few days, after which the growth of the Rossby wave train itself modifies both the divergence and vorticity fields, leading to perturbations in the wave source that eventually span the globe (not shown). The direct response to tropical heating in the Atlantic is a local perturbation to the Hadley circulation, which interacts with vorticity gradients on the subtropics, generating an anomalous Rossby wave source centered 


\section{A Rossby Wave source JJA}

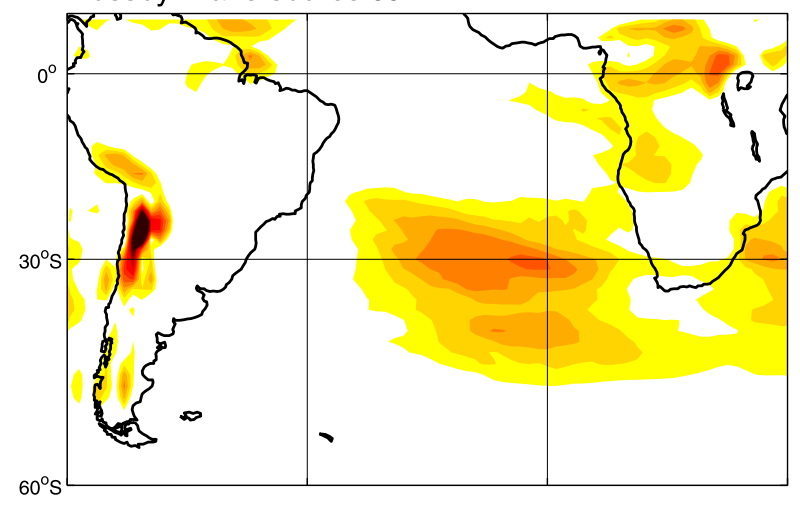

C Rossby Wave source DJF

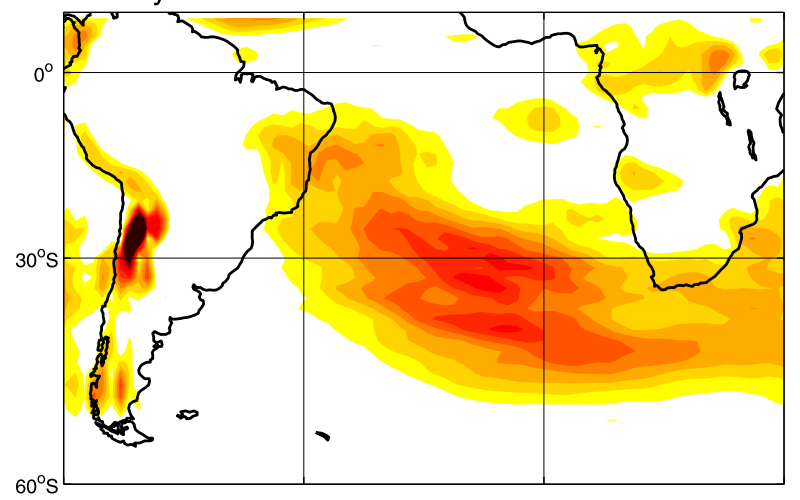

B Rossby Wave source SON

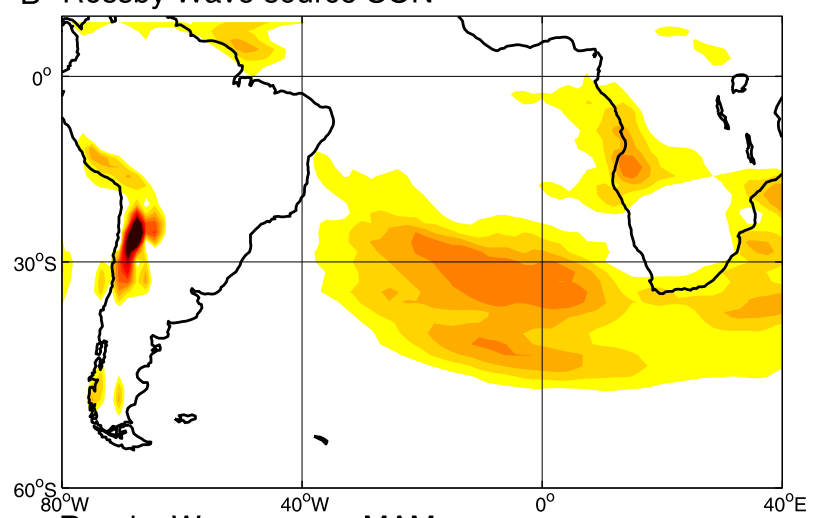

D Rossby Wave source MAM

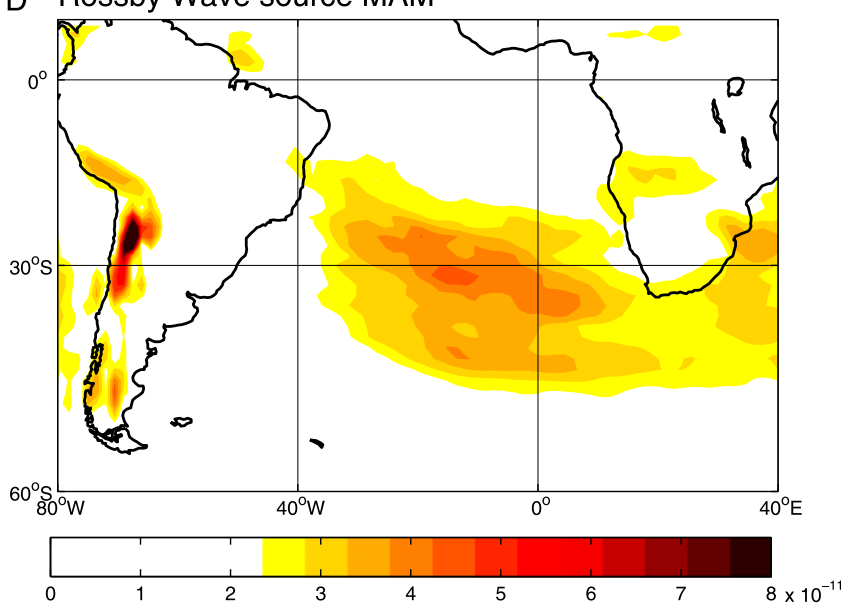

FIG. 9. The standard deviation of 200-hPa perturbation Rossby wave source (RWS) over southern Atlantic Ocean for the different seasons. The unit of the color shading is $\mathrm{s}^{-1}$.

about $15^{\circ} \mathrm{S}$ by day 3 (Fig. $8 \mathrm{a}$ ). Even at this early stage there are hints of the spread in the source perturbation over Africa, associated with eastward propagation of the Rossby wave train illustrated in Fig. 7. By day 6 (Fig. 8b), the perturbation to $S$ associated with the tropical heating penetrates well into the subtropics, in addition to spreading farther eastward over the Pacific.

Figures $8 \mathrm{c}$ and $8 \mathrm{~d}$ show the Rossby wave source in the DJF initial value calculation. The initial direct response to tropical warming is similar in this season as in winter, albeit shifted slightly equatorward. We again observe a spread in $S$ toward the extratropics, reaching past $30^{\circ} \mathrm{S}$ by day 6 , but differences between the DJF and JJA responses are more visible at this time. As can be seen by comparing Figs. 8b and 8d, the Rossby wave source on day 6 is weaker in DJF than in JJA, does not penetrate as far poleward, and appears more zonally localized (cf. Figs. $8 \mathrm{~b}$ and $8 \mathrm{~d}$ ). These variations in the Rossby wave source depend primarily on differences in the climatological flow between DJF and JJA, more so than differences in anomalous divergence and vorticity generated by the heating itself. This may partially explain why the Rossby wave trains in Fig. 8 are more intense in winter than in summer, and so helps explain the seasonality of the Atlantic-Antarctic teleconnection.

The time evolution and subsequent spread of the Rossby wave source to a localized heating makes it difficult to compute the response in the wave source to Atlantic warming in the CAM4 simulations or reanalysis. We can, however, estimate the availability of Rossby wave activity by focusing on the natural variability. Figure 9 shows the standard deviation in the Rossby wave source $S$ at $200 \mathrm{hPa}$ in ERA-Interim as a function of season. In all four seasons, there is a region of strong variance in $S$ centered over the subtropical Atlantic area (around $30^{\circ} \mathrm{S}$ ), consistent with the shortterm response of $S$ to tropical Atlantic warming in the initial-value calculations. The variances in the Rossby wave source in MAM, JJA, and SON are almost equal, and share the same spatial structures, while there is in fact stronger variance in the Rossby wave source in austral summer. Overall, however, there does not 
appear to be clear seasonal structure to the variability of the Rossby wave source.

\section{b. Rossby wave ray tracing}

The initial-value calculations suggest that warming in the tropical Atlantic generates Rossby waves on the equatorial flank of the midlatitude jet over the South Atlantic. The Rossby wave tracing theory developed by Hoskins and Karoly (1981) and Hoskins and Ambrizzi (1993) allows us to characterize the impact of the climatological state on the subsequent evolution of the stationary wave train.

For simplicity, we illustrate the wave tracing argument in Cartesian coordinates. Following Hoskins and Karoly (1981), we begin with the dispersion relation of a barotropic Rossby wave,

$$
\omega=U k-\frac{\beta^{*} k}{K^{2}},
$$

where $\omega$ is the frequency, $U$ is the zonal wind, $K=\sqrt{l^{2}+k^{2}}$ is the total wavenumber, $k$ and $l$ are the zonal and meridional wavenumbers, respectively; and $\beta^{*}=\beta-U_{y y}$ is the meridional gradient of the absolute vorticity of the mean flow where $\beta$ is the gradient in planetary vorticity and $U_{y y}$ is curvature of the flow. For a stationary wave, the frequency $\omega$ is zero, so that Eq. (2) leads to

$$
K^{2}=\beta^{* / U} .
$$

Even though the waves themselves are stationary, the wave train evolves according to the propagation of wave energy, which is given by the group velocity. Using Eq. (2), the group velocity of the stationary Rossby wave packet is

$$
\begin{aligned}
& c_{\mathrm{gx}}=\frac{\partial \omega}{\partial k}=\frac{2 \beta^{*} k^{2}}{K^{2}} \text { and } \\
& c_{\mathrm{gy}}=\frac{\partial \omega}{\partial l}=\frac{2 \beta^{*} k l}{K^{2}} .
\end{aligned}
$$

Thus the wave front propagates at the following angle:

$$
\frac{d x}{d y}=\frac{c_{\mathrm{gx}}}{c_{\mathrm{gy}}}=\frac{k}{l},
$$

which will allow us to trace the trajectory of the wave train as follows.

For each zonal wavenumber $k$ and a given starting point (i.e., initial position within the region where the Rossby wave source has been perturbed), we use Eq. (3) to solve for $l$. Equation (5) then tells us the initial trajectory of the ray. We step forward along this ray to a new point, and again use Eqs. (3) and (5) to compute the next step along the ray. The calculations were performed numerically and account for the spherical geometry. As the spatial scale of Rossby waves is always larger than $1000 \mathrm{~km}$, we first smooth the background fields of $\beta^{*}$ and $U$ with a Gaussian filter of radius $1000 \mathrm{~km}$ to eliminate the potential impacts of the small-scale structures in the background flow.

Note that Eq. (3) does not constrain the sign of $l$. By convention, we set $k$ to be positive, so that the sign of $l$ determines the meridional propagation of the ray: northward (i.e., equatorward in the austral hemisphere) for positive $l$ and southward for negative $l$. From the starting point, we begin tracing the poleward propagating wave packet, with $l<0$. The ray continues to propagate poleward ( $l$ remains negative) until we reach a point where either 1) $K^{2}=k^{2}$ and thus $l=0$ or 2) $K^{2}$ (and so $l$ ) approaches infinity. Case 1 occurs when the climatological vorticity gradient $\beta^{*}$ becomes small or zonal wind $U$ becomes large, creating a reflecting surface. The wave packet will be reflected and propagate in the opposite direction, so we reverse the sign of $l$ and trace it onward in the opposite direction. In the region where $\beta^{*} / U=K^{2}<k^{2}$ on the other side of the reflecting surface, the wave will be evanescent ( $l$ imaginary). Case 2 occurs when the zonal wind $U$ drops to zero, which is a critical line for a stationary wave $(U=c=0)$. In regions with $U<0$, the flow cannot support Rossby wave propagation - that is, we would expect nonlinear wave breaking to occur-and the ray is terminated.

To capture the impact of variations in the background climatological flow, we invoke the WKBJ approximation (as in Hoskins and Karoly 1981) and assume that variations are slow relative to the scale of the wave. This approximation is valid for small-scale waves but may be somewhat questionable for the largest planetary-scale waves. In addition, we allow for longitudinal variations in the mean flow. Equation (2) is strictly only valid for zonally symmetric flow, but one can neglect the terms involving the advection of zonal gradients in the absolute vorticity if these gradients are weak relative to the meridional gradients of absolute vorticity. Formally, Eq. (2) is still valid if the zonal gradients in the background vorticity are of the same order as the perturbation, so that the zonal advection of the absolute vorticity is comparable to the nonlinear terms involving the perturbation, which are also neglected. As the background flow is organized in jets, zonal gradients in the vorticity are generally much smaller than the meridional gradients, with the possible exception of the exit region of the subtropical jet in the east Pacific, away from the region of our focus.

As shown in Fig. 10, we trace wave packets associated with zonal wavenumbers $k=3$ from several initial 


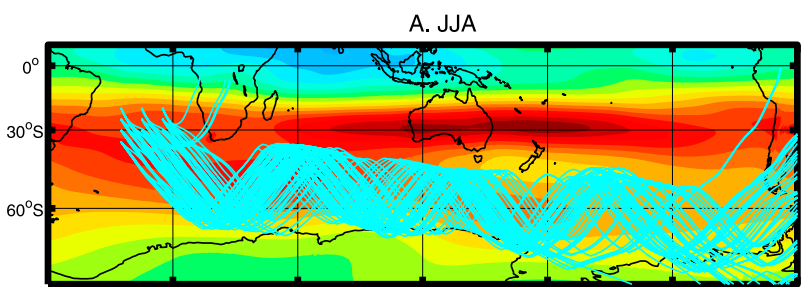

C. DJF
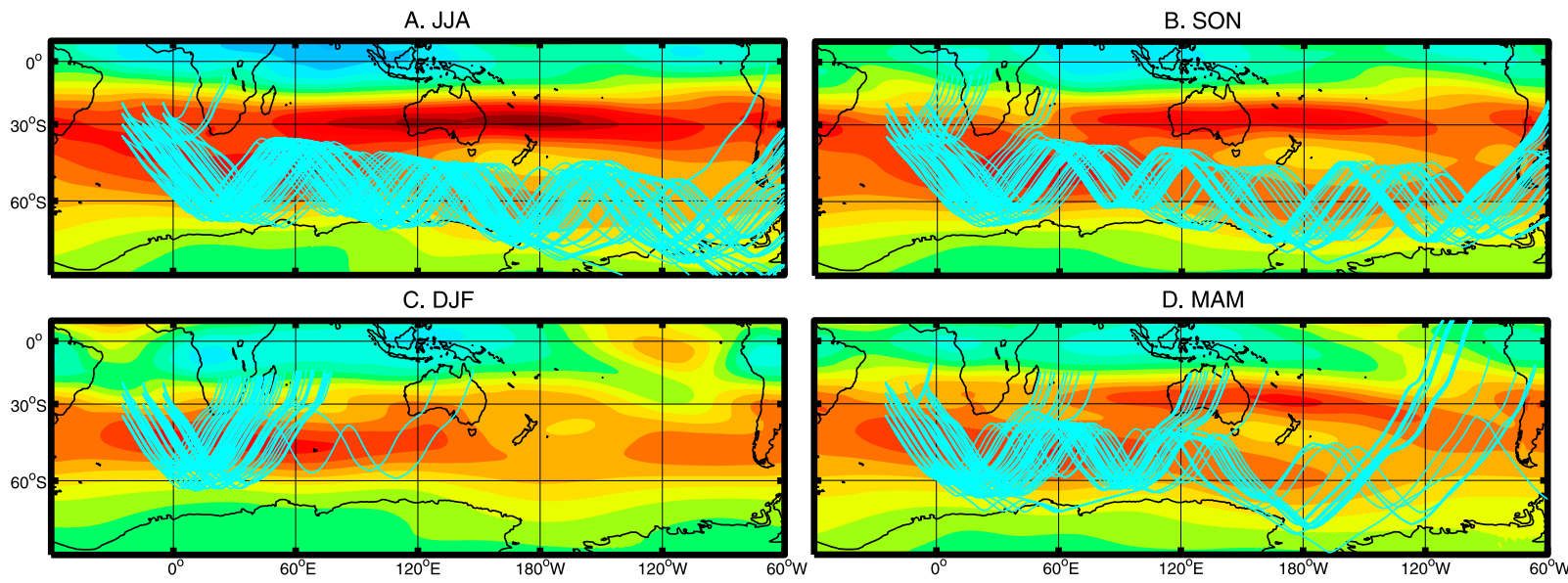

D. MAM

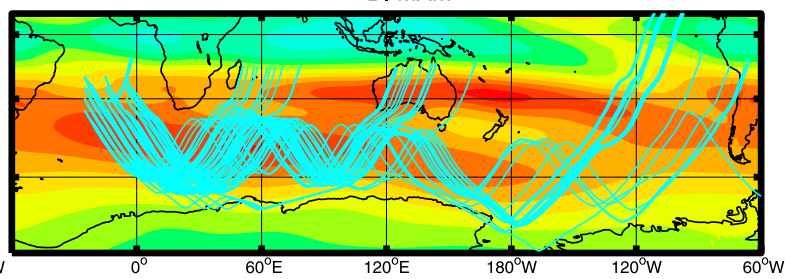

FIG. 10. The stationary Rossby wave trajectories (Persian green) with zonal wavenumber $k=3$. The Rossby waves start from subtropical Atlantic following the RWS analyses and are forced by the background states of different periods (5 yr each) from 1979 to 2012. Results are shown for austral (a) winter (JJA), (b) spring (SON), (c) summer (DJF), and (d) autumn (MAM), respectively. The background color shading indicates the climatological mean zonal wind, which serves as background fields of the Rossby wave trains.

points located within the subtropical Atlantic Rossby wave source region in each season. Multiple launch points were chosen in part to account for the fact that the Rossby wave source extends over a wide region, but also to better sample the effect of the background state on wave propagation; waves of scale $k=3$ will respond to gradients on scales equivalent to the wave itself. To ensure that the trajectories are not overly sensitive to the particular structure of the background flow, we also plot results based on several 5-yr mean background states from 1979 to 2012. The plots can thus be considered as an ensemble simulation of the Rossby wave trajectories, seeking to explore the potential range of paths take by stationary Rossby wave trains. Trajectories based on wavenumbers $k=2$ and $k=4$ exhibit qualitatively similar paths, and thus are not shown, for brevity.

The initial propagation of the rays is similar in all seasons: the wave packets propagate poleward from the subtropical South Atlantic until they are reflected by the weak vorticity gradients in the polar regions (where $\beta^{*} / U$ tends toward $k^{2}$ ). Differences between the seasons and wavenumbers, however, appear in the subsequent propagation of the equatorward propagating ray.

In DJF, nearly all rays continue propagating equatorward until they dissipate at critical latitudes in the subtropics. In other seasons, however, the rays interact with a second reflecting surface created by anticyclonic shear associated with the poleward flank of the subtropical jet and the equatorward flank of the midlatitude jet stream. In all seasons except summer, this reflecting surface is sufficiently strong to keep the wave activity in the extratropics, focusing the rays around the globe to the ABSL region. Ray tracing suggests that waves may be reflected multiple times, although we caution over interpretation of the ray as the literal path of the wave packet-especially as this finescale structure stretches the WKBJ assumption. Calculations based on wavenumbers 2 and 4 (not shown) yield slightly varying trajectories but generally suggest the same story: in autumn, winter, and spring, strong reflecting surfaces on the polar flank of the subtropical jet and midlatitude jet keep wave activity trapped in the extratropics, channeling it all the way to the Amundsen Sea region. In summer, however, the subtropical reflecting surface is too weak, and rays escape to the subtropics where wave activity is dissipated at critical lines.

To better illustrate the waveguide created by the subtropical jet and midlatitude jet, we show the total wavenumber $K=\sqrt{\left(\beta-U_{y y}\right) / U}$ for the four different seasons in Figs. 11a-d. Regions where $K$ tends toward zero (the boundaries of the white regions) mark reflecting surfaces, while regions where $K$ tends to infinity (the boundaries of the gray regions) indicate the presence of critical latitudes where wave activity is dissipated. There exist two key reflecting regions in the Southern Hemisphere: a polar low- $\beta$ sector (present in all seasons) and a subtropical band between $30^{\circ}$ and $40^{\circ} \mathrm{S}$, present in all seasons but summer. These two regions create a waveguide for Rossby wave activity that channels rays to the ABSL region, as in Fig. 10.

The climatological meridional vorticity gradient $\left(\beta-U_{y y}\right)$ as a function of season is plotted in Figs. 11e-h and illustrates the underlying cause of the reflecting surfaces. The polar reflecting surface is a consequence of the decline in $\beta^{*}$ (associated with the decline in $\beta$ ) as one 

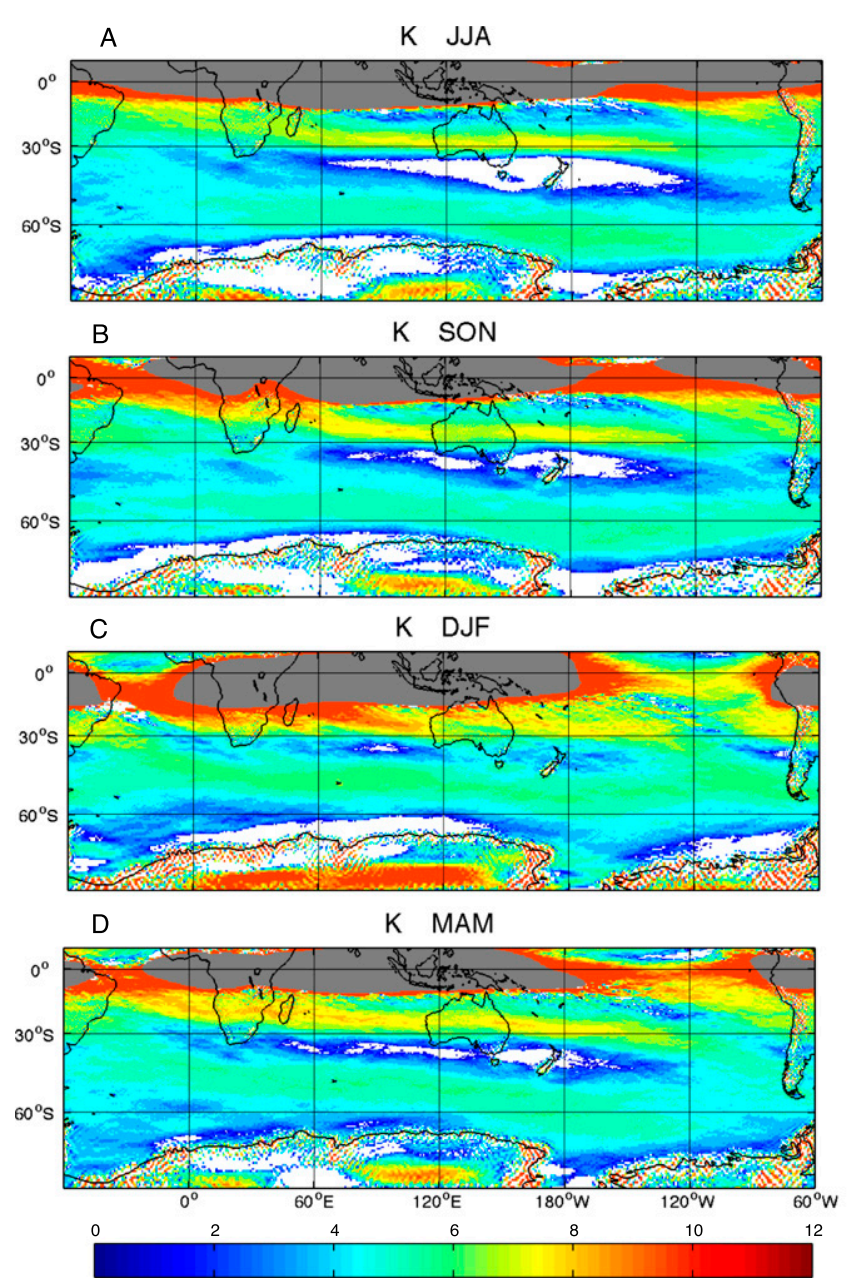
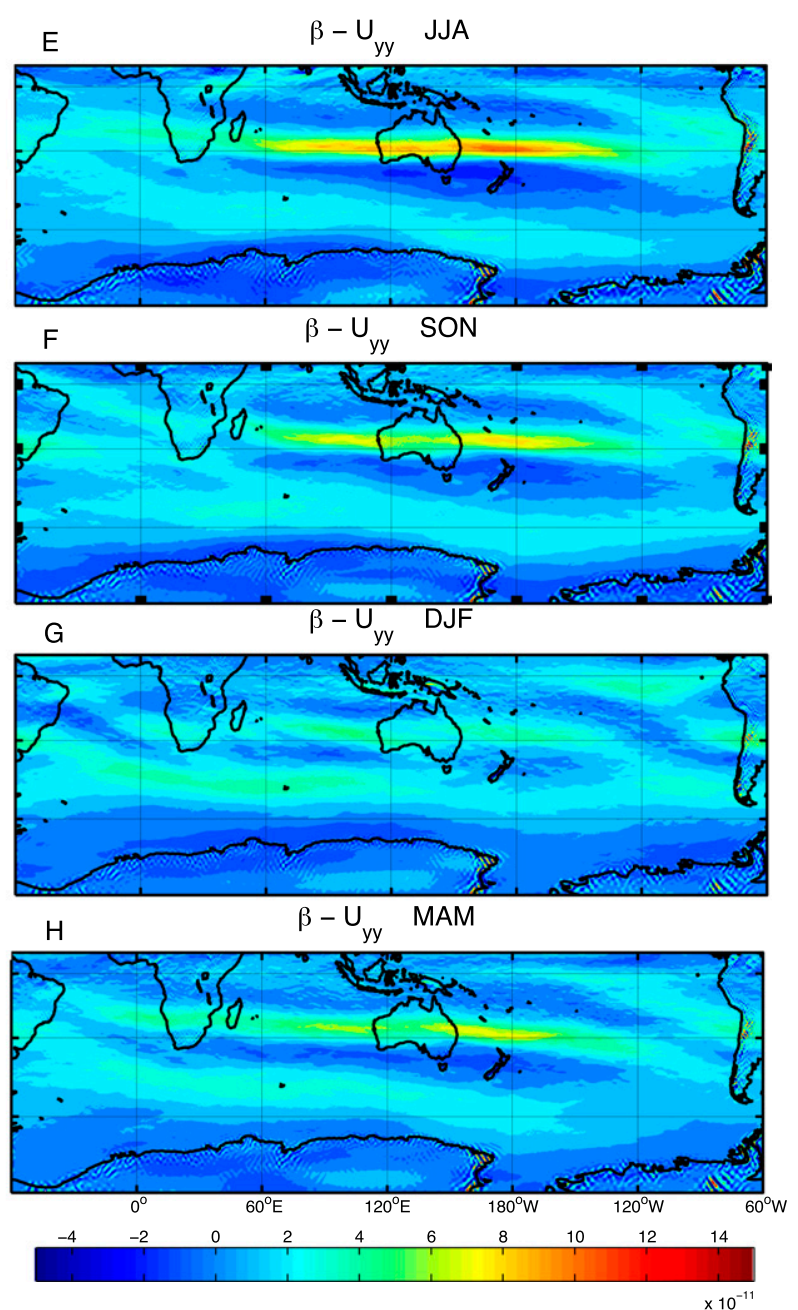

FIG. 11. The climatological (a)-(d) total Rossby wave number $\left(\mathrm{m}^{-1}\right)$ and (e),(f) meridional gradient of absolute vorticity in ERAInterim data $\left(\mathrm{m}^{-1} \mathrm{~s}^{-1}\right)$ in four seasons. The white areas indicate the regions where the total wavenumber is imaginary because of a negative meridional gradient of vorticity, while the gray areas indicate the regions where the total wavenumber is imaginary because of the easterly trade wind. The stationary Rossby wave trains will be reflected by the edge of the white region but break when arriving at the gray region.

approaches the pole. The subtropical reflecting surface, however, owes its existence to the curvature of the flow $\left(U_{y y}\right)$ along the polar flank of the subtropical jet and equatorward flank of the midlatitude jet stream, which is sometimes sufficiently strong to overcome the gradient in planetary vorticity $\beta$. Regions of negative $\beta^{*}$ are marked in dark blue, and are most prominent over the west Pacific in JJA and MAM. This reversal in the vorticity gradient forms a barrier to Rossby wave propagation, keeping the wave activity trapped in the extratropics-in all seasons but summer when the subtropical jet is too weak to counteract the planetary vorticity gradient.

We acknowledge the fact that Rossby wave ray tracing relies on fairly crude assumptions about wave propagation, greatly simplifying true Rossby wave dynamics.
However, the strong coherence between observational analyses, the response of the comprehensive (CAM4) and idealized (GFDL dynamical core) models, and this analytic model for wave propagation makes a strong argument that the teleconnection is closely associated with the Rossby wave dynamics and depends critically on the background flow.

\section{Conclusions and discussion}

In this study, we have established the Rossby wave train mechanism for the Atlantic-Antarctica teleconnection proposed by $\mathrm{Li}$ et al. (2014), and further explored by Simpkins et al. (2014). Warming of the tropical Atlantic, potentially associated with the Atlantic multidecadal 
oscillation pattern of SST variability, drives a positive phase anomaly in the southern annular mode, deepening the Amundsen-Bellingshausen Seas low. Here, we have established that this atmospheric bridge is present in all seasons except austral summer, and have shown that it depends critically on differences in Rossby wave generation and the formation of a Rossby waveguide across the Pacific, which directs quasi-stationary Rossby waves from the Atlantic to the Amundsen Sea. The northern boundary of the waveguide is created by anticyclonic shear between the subtropical and midlatitude jets. In all seasons but austral summer, the shear is sufficiently strong to channel wave activity all the way to the Amundsen Sea. In summer, however, the weakening of the subtropical jet allows wave activity to escape to the subtropics, where Rossby wave propagation is subsequently inhibited by easterly winds.

The seasonality of the teleconnection was first suggested by regression analysis of MERRA and ERAInterim. The causality-the fact that SST anomalies are in fact driving the atmospheric patterns-was then established with prescribed SST experiments in a comprehensive atmospheric model, CAM4. The prescribed SST experiments also allowed us to establish the linearity of the atmospheric response to tropical SSTs, supporting a linear Rossby wave mechanism. We then simulated the large-scale circulation response to tropical warming in an idealized dry-dynamical core, isolating the impact of Rossby wave dynamics. The simple primitive equation model captures the key elements of the teleconnection, as highlighted in Fig. 4.

Calculations of the Rossby wave source (Sardeshmukh and Hoskins 1988) suggested that the disappearance of the teleconnection in summer is partly influenced by differences in wave generation. The initial-value calculations with the dynamical core allowed us to see the direct response of the atmosphere to tropical heating and showed that wave activity is generated in both winter and summer, but is more equatorially trapped in the latter season. This may explain why the wave train never fully develops in summer, even locally in the Atlantic sector, as seen in the initial-value calculations in Fig. 7. Natural variability in the wave source, which can be assessed in the reanalysis, suggests the presences of wave forcing in the subtropical South Atlantic in all seasons, indicating that propagation also plays a role.

Rossby ray tracing in the theoretical framework of Hoskins and Karoly (1981) allowed us to show how changes in the zonal winds with season influence the teleconnection. This analysis highlights the role of the subtropical and midlatitude jets in guiding the wave trains to the Amundsen Sea region. Anticyclonic shear on the poleward flank of the subtropical jet can sufficiently weaken - and potentially even reverse-the meridional gradient in absolute vorticity, forming a barrier to Rossby wave propagation. In austral summer, however, this jet is too weak to contain the Rossby wave activity, and the wave trains no longer reach the Amundsen-Bellingshausen Seas region, explaining the loss of the teleconnection in this season.

The role of poleward propagating Rossby wave trains in tropical-polar teleconnections has been studied in some detail in the past. Previous studies, however, have focused primarily on the Pacific-Antarctic interaction (Karoly 1989; Fogt et al. 2011; Ding et al. 2011). Our study offers a new perspective in relating the Antarctic climate variability to the tropical Atlantic. Li et al. (2014) suggested that this teleconnection might explain a significant fraction of both the recent warming of the Antarctic Peninsula and the redistribution of sea ice between the Ross and Amundsen-Bellingshausen Seas. In addition, the circulation changes over the Southern Hemisphere could also impact on the weather and climate in Australia, New Zealand (Thompson et al. 2011), and South America (Seager et al. 2010).

A better understanding of this Atlantic-Antarctica teleconnection may prove important for improving our ability to simulate and predict climate variability in these regions. The AMO has been associated with the meridional overturning circulation of the Atlantic (Delworth and Mann 2000; Knight et al. 2005), which is in turn influenced by the formation of Antarctic bottom water in the Weddell Sea. The "atmospheric bridge" from the tropical North Atlantic to Antarctic explored in this study could thus potentially be coupled with an "oceanic bridge" from the Antarctic to the North Atlantic associated with the meridional overturning circulation.

Antarctic climate is also influenced by other tropicalpolar teleconnections (Fogt et al. 2011; Ding et al. 2012), and key questions remain concerning the relative importance of these effects. The time scales of tropical SST variability differs significantly from one region to another (e.g., ENSO and the east Pacific dominate on interannual time scales, while the AMO and Pacific decadal oscillation are more significant on longer time scales). Moreover, SSTs in different tropical ocean basins may interact with each other through tropical ocean interbasin teleconnections. It is thus important to further investigate the relative importance and the relationship between the teleconnections from different tropical ocean sectors as a function of time scale.

Acknowledgments. We thank Qinghua Ding and two anonymous reviewers for their insightful comments on earlier versions of the manuscript. X.L., D.M.H., and C.Y. were supported by the NSF Office of Polar 
Programs ANT-0732869, the NASA Polar Programs NNX12AB69G, and the New York University Abu Dhabi G1204. E.P.G. was supported by the National Science Foundation (NSF) Division of Atmospheric and Geospace Sciences through Grant AGS-1264195. The HadISST sea surface temperature and sea-ice concentration data were provided by the British Met Office Hadley Centre. The Antarctic weather station data were made available by the British Antarctic Survey (BAS). The MERRA atmospheric reanalysis data were provided by the Global Modeling and Assimilation Office (GMAO) at NASA Goddard Space Flight Center (GSFC) through the NASA Goddard Earth Sciences (GES) Data and Information Services Center (DISC) online archive. The ERA-Interim atmospheric reanalysis was provided by the European Centre for Medium-Range Weather Forecasts (ECMWF). The comprehensive atmospheric model, CAM4, was made available by the National Center for Atmospheric Research (NCAR), supported by the National Science Foundation (NSF) and the Office of Science of the U.S. Department of Energy (DOE). The idealized atmospheric model, GFDL drydynamical-core, was developed by the National Oceanic and Atmospheric Administration (NOAA)/Geophysical Fluid Dynamics Laboratory (GFDL). Computing resources were provided by the National Energy Research Scientific Computing Center (NERSC) and High Performance Computing (HPC) center at New York University (NYU).

\section{REFERENCES}

Arblaster, J. M., and G. A. Meehl, 2006: Contributions of external forcings to southern annular mode trends. J. Climate, 19, 28962905, doi:10.1175/JCLI3774.1.

Bretherton, C. S., M. Widmann, V. P. Dymnikov, J. M. Wallace, and I. Bladé, 1999: The effective number of spatial degrees of freedom of a time-varying field. J. Climate, 12, 1990-2009, doi:10.1175/1520-0442(1999)012<1990:TENOSD>2.0.CO;2.

Bromwich, D. H., J. P. Nicolas, A. J. Monaghan, M. A. Lazzara, L. M. Keller, G. A. Weidner, and A. B. Wilson, 2013: Central West Antarctica among the most rapidly warming regions on Earth. Nat. Geosci., 6, 139-145, doi:10.1038/ngeo1671.

Butler, A. H., D. W. J. Thompson, and K. R. Gurney, 2007: Observed relationships between the southern annular mode and atmospheric carbon dioxide. Global Biogeochem. Cycles, 21, GB4014, doi:10.1029/2006GB002796.

Dee, D. P., and Coauthors, 2011: The ERA-Interim reanalysis: Configuration and performance of the data assimilation system. Quart. J. Roy. Meteor. Soc., 137, 553-597, doi:10.1002/qj.828.

Delworth, T. L., and M. E. Mann, 2000: Observed and simulated multidecadal variability in the Northern Hemisphere. Climate Dyn., 16, 661-676, doi:10.1007/s003820000075.

Ding, Q., E. J. Steig, D. S. Battisti, and M. Küttel, 2011: Winter warming in West Antarctica caused by central tropical Pacific warming. Nat. Geosci., 4, 398-403, doi:10.1038/ngeo1129.
,--1, - - and J. M. Wallace, 2012: Influence of the tropics on the southern annular mode. J. Climate, 25, 6330-6348, doi:10.1175/JCLI-D-11-00523.1.

Fogt, R. L., and D. H. Bromwich, 2006: Decadal variability of the ENSO teleconnection to the high-latitude South Pacific governed by coupling with the southern annular mode. J. Climate, 19, 979-997, doi:10.1175/JCLI3671.1.

,$- \ldots$, and K. M. Hines, 2011: Understanding the SAM influence on the South Pacific ENSO teleconnection. Climate Dyn., 36, 1555-1576, doi:10.1007/s00382-010-0905-0.

_ A. J. Wovrosh, R. A. Langen, and I. Simmonds, 2012: The characteristic variability and connection to the underlying synoptic activity of the Amundsen-Bellingshausen Seas low. J. Geophys. Res., 117, D07111, doi:10.1029/2011JD017337.

Franzke, C., S. Lee, and S. B. Feldstein, 2004: Is the North Atlantic Oscillation a breaking wave? J. Atmos. Sci., 61, 145-160, doi:10.1175/1520-0469(2004)061<0145:ITNAOA > 2.0.CO;2.

Gillett, N. P., and D. W. Thompson, 2003: Simulation of recent Southern Hemisphere climate change. Science, 302, 273-275, doi:10.1126/science. 1087440 .

Held, I. M., and M. J. Suarez, 1994: A proposal for the intercomparison of the dynamical cores of atmospheric general circulation models. Bull. Amer. Meteor. Soc., 75, 1825-1830, doi:10.1175/1520-0477(1994)075<1825:APFTIO>2.0.CO;2.

Hoskins, B. J., and D. J. Karoly, 1981: The steady linear response of a spherical atmosphere to thermal and orographic forcing. J. Atmos. Sci., 38, 1179-1196, doi:10.1175/1520-0469(1981)038<1179: TSLROA $>2.0 . \mathrm{CO} ; 2$.

— , and T. Ambrizzi, 1993: Rossby wave propagation on a realistic longitudinally varying flow. J. Atmos. Sci., 50, 1661-1671, doi:10.1175/1520-0469(1993)050<1661:RWPOAR > 2.0.CO;2.

Jacobs, S. S., and J. C. Comiso, 1997: Climate variability in the Amundsen and Bellingshausen Seas. J. Climate, 10, 697-709, doi:10.1175/1520-0442(1997)010<0697:CVITAA > 2.0.CO;2.

Jin, F., and B. J. Hoskins, 1995: The direct response to tropical heating in a baroclinic atmosphere. J. Atmos. Sci., 52, 307-319, doi:10.1175/1520-0469(1995)052<0307:TDRTTH >2.0.CO;2.

Karoly, D. J., 1989: Southern Hemisphere circulation features associated with El Niño-Southern Oscillation events. J. Climate, 2, 1239-1252, doi:10.1175/1520-0442(1989)002<1239: SHCFAW $>2.0 . \mathrm{CO} ; 2$.

Knight, J. R., R. J. Allan, C. K. Folland, M. Vellinga, and M. E. Mann, 2005: A signature of persistent natural thermohaline circulation cycles in observed climate. Geophys. Res. Lett., 32 , L20708, doi:10.1029/2005GL024233.

Lefebvre, W., and H. Goosse, 2005: Influence of the southern annular mode on the sea ice-ocean system: The role of the thermal and mechanical forcing. Ocean Sci., 1, 145-157, doi:10.5194/ os-1-145-2005.

,,-- R. Timmermann, and T. Fichefet, 2004: Influence of the southern annular mode on the sea ice-ocean system. J. Geophys. Res., 109, C09005, doi:10.1029/2004JC002403.

L'Heureux, M. L., and D. W. J. Thompson, 2006: Observed relationships between the El Niño-Southern Oscillation and the extratropical zonal-mean circulation. J. Climate, 19, 276-287, doi:10.1175/JCLI3617.1.

Li, X., D. M. Holland, E. P. Gerber, and C. Yoo, 2014: Impacts of the north and tropical Atlantic Ocean on the Antarctic Peninsula and sea ice. Nature, 505, 538-542, doi:10.1038/ nature12945.

Liu, J., J. A. Curry, and D. G. Martinson, 2004: Interpretation of recent Antarctic sea ice variability. Geophys. Res. Lett., 31, L02205, doi:10.1029/2003GL018732. 
Lovenduski, N. S., and N. Gruber, 2005: Impact of the southern annular mode on Southern Ocean circulation and biology. Geophys. Res. Lett., 32, L11603, doi:10.1029/2005GL022727.

,-- S. C. Doney, and I. D. Lima, 2007: Enhanced $\mathrm{CO}_{2}$ outgassing in the Southern Ocean from a positive phase of the southern annular mode. Global Biogeochem. Cycles, 21, GB2026, doi:10.1029/2006GB002900.

Marshall, G. J., 2003: Trends in the southern annular mode from observations and reanalyses. J. Climate, 16, 4134-4143, doi:10.1175/1520-0442(2003)016<4134:TITSAM > 2.0.CO;2.

Okumura, Y. M., D. Schneider, C. Deser, and R. Wilson, 2012: Decadal-interdecadal climate variability over Antarctica and linkages to the tropics: Analysis of ice core, instrumental, and tropical proxy data. J. Climate, 25, 7421-7441, doi:10.1175/ JCLI-D-12-00050.1.

Parkinson, C. L., 2004: Southern Ocean sea ice and its wider linkages: Insights revealed from models and observations. Antarct. Sci., 16, 387-400, doi:10.1017/S0954102004002214.

Pritchard, H. D., S. R. M. Ligtenberg, H. A. Fricker, D. G. Vaughan, M. R. Van den Broeke, and L. Padman, 2012: Antarctic ice-sheet loss driven by basal melting of ice shelves. Nature, 484, 502-505, doi:10.1038/nature10968.

Rayner, N. A., D. E. Parker, E. B. Horton, C. K. Folland, L. V. Alexander, D. P. Rowell, E. C. Kent, and A. Kaplan, 2003: Global analyses of sea surface temperature, sea ice, and night marine air temperature since the late nineteenth century. J. Geophys. Res., 108, 4407, doi:10.1029/ 2002JD002670.

Rienecker, M. M., and Coauthors, 2011: MERRA: NASA's ModernEra Retrospective Analysis for Research and Applications. J. Climate, 24, 3624-3648, doi:10.1175/JCLI-D-11-00015.1.

Sardeshmukh, P. D., and B. J. Hoskins, 1988: The generation of global rotational flow by steady idealized tropical divergence. J. Atmos. Sci., 45, 1228-1251, doi:10.1175/ 1520-0469(1988)045<1228:TGOGRF>2.0.CO;2.

Schlesinger, M. E., and N. Ramankutty, 1994: An oscillation in the global climate system of period 65-70 years. Nature, 367, 723726, doi:10.1038/367723a0.

Schneider, D., Y. Okumura, and C. Deser, 2012: Observed Antarctic interannual climate variability and tropical linkages. J. Climate, 25, 4048-4066, doi:10.1175/JCLI-D-11-00273.1.

Seager, R., N. Naik, W. Baethgen, A. Robertson, Y. Kushnir, J. Nakamura, and S. Jurburg, 2010: Tropical oceanic causes of interannual to multidecadal precipitation variability across southeast South America over the past century. J. Climate, 23, 5517-5539, doi:10.1175/2010JCLI3578.1.

Seo, K.-H., and S.-W. Son, 2012: The global atmospheric circulation response to tropical diabatic heating associated with the Madden-Julian oscillation during northern winter. J. Atmos. Sci., 69, 79-96, doi:10.1175/2011JAS3686.1.
Shepherd, A., and Coauthors, 2012: A reconciled estimate of ice-sheet mass balance. Science, 338, 1183-1189, doi:10.1126/science.1228102.

Sigmond, M., and J. C. Fyfe, 2010: Has the ozone hole contributed to increased Antarctic sea ice extent? Geophys. Res. Lett., 37, L18502, doi:10.1029/2010GL044301.

Simpkins, G. R., S. McGregor, A. S. Taschetto, L. M. Ciasto, and M. H. England, 2014: Tropical connections to climatic change in the extratropical Southern Hemisphere: The role of Atlantic SST trends. J. Climate, 27, 4923-4936, doi:10.1175/JCLI-D-13-00615.1.

Stammerjohn, S. E., D. G. Martinson, R. C. Smith, X. Yuan, and D. Rind, 2008: Trends in Antarctic annual sea ice retreat and advance and their relation to El Niño-Southern Oscillation and southern annular mode variability. J. Geophys. Res., 113, C03S90, doi:10.1029/2007JC004269.

Thompson, D. W. J., and J. M. Wallace, 2000: Annular modes in the extratropical circulation. Part I: Month-to-month variability. J. Climate, 13,1000-1016, doi:10.1175/1520-0442(2000)013<1000: AMITEC $>2.0 . \mathrm{CO} ; 2$.

, and S. Solomon, 2002: Interpretation of recent Southern Hemisphere climate change. Science, 296, 895-899, doi:10.1126/ science. 1069270.

_ J. M. Wallace, and G. C. Hegerl, 2000: Annular modes in the extratropical circulation. Part II: Trends. J. Climate, 13, 1018-1036, doi:10.1175/1520-0442(2000)013<1018:AMITEC >2.0.CO;2.

— S. Solomon, P. J. Kushner, M. H. England, K. M. Grise, and D. J. Karoly, 2011: Signatures of the Antarctic ozone hole in Southern Hemisphere surface climate change. Nat. Geosci., 4, 741-749, doi:10.1038/ngeo1296.

Turner, J., T. Phillips, J. S. Hosking, G. J. Marshall, and A. Orr, 2013: The Amundsen Sea low. Int. J. Climatol., 33, 1818-1829, doi:10.1002/joc. 3558 .

Vaughan, D. G., G. J. Marshall, W. M. Connolley, J. C. King, and R. Mulvaney, 2001: Devil in the detail. Science, 293, 17771779, doi:10.1126/science.1065116.

_ - and Coauthors, 2003: Recent rapid regional climate warming on the Antarctic Peninsula. Climatic Change, 60, 243-274, doi:10.1023/A:1026021217991.

Yoo, C., S. Lee, and S. B. Feldstein, 2012: Arctic response to an MJO-like tropical heating in an idealized GCM. J. Atmos. Sci., 69, 2379-2393, doi:10.1175/JAS-D-11-0261.1.

Yuan, X., 2004: ENSO-related impacts on Antarctic sea ice: A synthesis of phenomenon and mechanisms. Antarct. Sci., 16, 415-425, doi:10.1017/S0954102004002238. , and D. G. Martinson, 2001: The Antarctic dipole and its predictability. Geophys. Res. Lett., 28, 3609-3612, doi:10.1029/ 2001 GL012969.

Zwally, H. J., W. Abdalati, T. Herring, K. Larson, J. Saba, and K. Steffen, 2002: Surface melt-induced acceleration of Greenland ice-sheet flow. Science, 297, 218-222, doi:10.1126/ science.1072708. 